\title{
Experimental and Numerical Investigation of the ECAP Processed Copper: Microstructural Evolution, Crystallographic Texture and Hardness Homogeneity
}

\author{
A. I. Alateyah ${ }^{1, *}$, Mohamed M. Z. Ahmed ${ }^{2,3}\left(\mathbb{D}\right.$, Yasser Zedan ${ }^{4}$, H. Abd El-Hafez 1,5 ${ }^{(D)}$ Majed O. Alawad ${ }^{6, *(\mathbb{D})}$ \\ and W. H. El-Garaihy 1,7 (D)
}

check for

updates

Citation: Alateyah, A.I.; Ahmed, M.M.Z.; Zedan, Y.; El-Hafez, H.A.; Alawad, M.O.; El-Garaihy, W.H. Experimental and Numerical Investigation of the ECAP Processed Copper: Microstructural Evolution, Crystallographic Texture and Hardness Homogeneity. Metals 2021, 11, 607. https://doi.org/10.3390/ met11040607

Academic Editor: Sónia Simões

Received: 10 March 2021

Accepted: 6 April 2021

Published: 9 April 2021

Publisher's Note: MDPI stays neutra with regard to jurisdictional claims in published maps and institutional affiliations.

Copyright: (c) 2021 by the authors. Licensee MDPI, Basel, Switzerland. This article is an open access article distributed under the terms and conditions of the Creative Commons Attribution (CC BY) license (https:/ / creativecommons.org/licenses/by/ $4.0 /)$.
1 Department of Mechanical Engineering, College of Engineering, Qassim University, Unaizah 56452, Saudi Arabia; HM.Ahmed@qu.edu.sa (H.A.E.-H.); W.Nasr@qu.edu.sa (W.H.E.-G.)

2 Mechanical Engineering Department, College of Engineering at Al Kharj, Prince Sattam Bin Abdulaziz University, Al Kharj 11942, Saudi Arabia; moh.ahmed@psau.edu.sa

3 Metallurgical and Materials Engineering Department, Faculty of Petroleum and Mining Engineering, Suez University, Suez 43511, Egypt

4 École de technologie supérieure, Department of Mechanical Engineering, 1100 Notre-Dame West, Montreal, QC H4J 1J9, Canada; yasser.zedan@etsmtl.ca

5 Production Engineering and Mechanical Design Department, Faculty of Engineering, Port-Said University, Port-Said 42523, Egypt

6 Materials Science Research Institute, King Abdulaziz City for Science and Technology (KACST), Riyadh 11442, Saudi Arabia

7 Mechanical Engineering Department, Faculty of Engineering, Suez Canal University, Ismailia 41522, Egypt

* Correspondence: a.alateyah@qu.edu.sa (A.I.A.); moalawad@kacst.edu.sa (M.O.A.); Tel.: +966-055-313-3322 (A.I.A.)

Abstract: The current study presents a detailed investigation for the equal channel angular pressing of pure copper through two regimes. The first was equal channel angular pressing (ECAP) processing at room temperature and the second was ECAP processing at $200{ }^{\circ} \mathrm{C}$ for up to 4-passes of route Bc. The grain structure and texture was investigated using electron back scattering diffraction (EBSD) across the whole sample cross-section and also the hardness and the tensile properties. The microstructure obtained after 1-pass at room temperature revealed finer equiaxed grains of about $3.89 \mu \mathrm{m}$ down to submicrons with a high density of twin compared to the starting material. Additionally, a notable increase in the low angle grain boundaries (LAGBs) density was observed. This microstructure was found to be homogenous through the sample cross section. Further straining up to 2-passes showed a significant reduction of the average grain size to $2.97 \mu \mathrm{m}$ with observable heterogeneous distribution of grains size. On the other hand, increasing the strain up to 4-passes enhanced the homogeneity of grain size distribution. The texture after 4-passes resembled the simple shear texture with about 7 times random. Conducting the ECAP processing at $200{ }^{\circ} \mathrm{C}$ resulted in a severely deformed microstructure with the highest fraction of submicron grains and high density of substructures was also observed. ECAP processing through 4-passes at room temperature experienced a significant increase in both hardness and tensile strength up to $180 \%$ and $124 \%$, respectively.

Keywords: ECAP; ultrafine-grained; severe plastic deformation; crystallographic texture; EBSD

\section{Introduction}

Copper $(\mathrm{Cu})$ and $\mathrm{Cu}$ alloys have been found to possess fairly high strength, outstanding thermal conductivity, resistance to corrosion while being easy to fabricate; as a result, they have gained popular appeal in applications like automobile manufacturing, railway transportation, electrical and electronic industries, structural applications and applications involving heating or temperature measurement [1-5]. Due to its known softness and ductility, industrially utilizing pure $\mathrm{Cu}$ is kept to a minimum in many engineering 
applications [6]. A common fix to this problem is the refinement of the grain structure on the nano-scale level using severe plastic deformation (SPD) techniques [7-9]. This produces ultrafine-grained (UFG) $\mathrm{Cu}$ that possesses many appealing properties such as the coexistence of high strength and ductility $[4,10,11]$.

Currently SPD methods have achieved wide circulation because of their effect on microstructure behavior. SPD can be used to produce UFG microstructures and to deform pure and alloy materials that directly causes the improvement of both the physical and mechanical properties and the corrosion behavior of the processed materials [12,13]. Among the plethora of SPD processes available now are high-pressure torsion (HPT) [14-17], twist extrusion (TE) [18-21], accumulative roll-bonding (ARB) [22] and ECAP [12,23-25]. Among these processes, the most applicable of them is ECAP, which allows for extremely large magnitudes of strain to be applied to a bulk sample through intensive simple shear; thus, ECAP is highly capable and efficient in fabricating different types of UFG and nanostructured materials (NS) [26-29]. Furthermore, the ductility of a material can be increased through ECAP since the improvement of a duplex microstructure formed by NS grains sized coupled with micrometric or UFG without sacrificing the martials strength [30]. As a result, of its relative simplicity and its ability to produce large amount of material, ECAP is an available candidate for further utilization and deployment in industry [31].

The ECAP process can be applied to samples of different shapes like rectangles, squares, or circles. The SPD of the microstructure occurs without any significant changes in dimensions, which means the materials can undergo an unlimited number of passes and can be pressed indefinitely to achieve a higher total strain [27]. The die of ECAP includes two channels with the same cross-section intersecting at a channel angle $\Phi$, and with an angle of curvature, $\Psi$. The equivalent plastic strain imposed to the ECAPed sample is largely dependent on the die angles and the number of processing passes [32]. The magnitude of equivalent effective plastic strain $\left(\varepsilon_{e q}\right)$ after $\mathrm{N}$ passes can be calculated from the following relationship [33]:

$$
\varepsilon_{e q}=\frac{N}{\sqrt{3}}\left[2 \cot \left(\frac{\varphi+\psi}{2}\right)+\psi \operatorname{cosec}\left(\frac{\varphi+\psi}{2}\right)\right]
$$

In addition, using a large number of ECAP passes increases friction between the processed billets and the die walls that results in increased density of the high-angle boundaries, which enhances the mechanical properties of the processed materials significantly $[23,25,28,34-36]$.

Several studies are investigating the effect of ECAP processing parameters on the microstructural evolution and mechanical properties of pure copper. Wang et al. [37] processed pure $\mathrm{Cu}$ with routes $\mathrm{Bc}, \mathrm{A}$ and new route has a specific rotation angle of the sample between consecutive passes called $\mathrm{X}$. They found that processing pure $\mathrm{Cu}$ via new route $X$ up to eight passes at room temperature (RT) is more effective than routes $\mathrm{A}$ and $\mathrm{Bc}$ in lower dislocation density and grain size in addition to improved strength and ductility of processed samples. As demonstrated by Guo et al. [38], ECAP processing led to a significant improvement in the strength of single crystal $\mathrm{Cu}$. Simultaneously, the plasticity and conductivity of $\mathrm{Cu}$ maintained excellent values. Blum et al. [39] observed that the microcrystalline grains resulting from ECAP processing through two passes were coarsening discontinuously during the creep test, which led to dramatic changes in the creep rate. Zhu et al. [40] found that the large initial pure $\mathrm{Cu}$ grains were refined after four ECAP passes, while processing for five to eight passes caused saturation and high density of dislocation cells with a size of $500 \mathrm{~nm}$ is evolved inside micron grains. On the other hand, the hardness distribution maps revealed the inhomogeneity of mechanical properties. A crystal plasticity finite element model had been developed by Deng et al. [41] to investigate the pure $\mathrm{Cu}$ texture evolution during ECAP. They reported that the crystallographic orientation was capable of rotation in three dimensions during ECAP, with higher rotation angles around the Z-axis. It is worth mentioning here that static recrystallization resulting from performing ECAP at $200{ }^{\circ} \mathrm{C}$ generates a homogenous structure as reported 
by Blum et al. [42]. Moreover, the ductility was significantly improved by worm processing. Ebrahimi et al. [43] reported that ECAP processing resulted in a non-uniform hardness distribution with lower hardness at the bottom region of commercial pure $\mathrm{Cu}$, which becomes more homogenous gradually by increasing the number of passes.

This study aims to provide a comprehensive analysis for the effect of ECAP on the mechanical properties, microstructural evolution, crystallographic texture, and hardness distribution across the ECAP processed commercial pure $\mathrm{Cu}$. To this aim, a unique EBSD analysis was carried out along the longitudinal section of the ECAPed $\mathrm{Cu}$ sample from the right peripheral regions passing through the central regions down to the left peripheral regions to investigate the influence of ECAP possessing through multiple passes on the microstructural homogeneity and crystallographic texture. Furthermore, the microhardness distribution was studied along both the longitudinal and transverse section and correlated with the EBSD analysis. For better presentation, the hardness profiles and their degrees of homogeneity were illustrated by 3 dimensional color-coded outlines. In addition, a numerical modeling was used to investigate the induced effective stress-strain and their distribution along the $\mathrm{Cu}$ processed samples and compared with the experimental findings. Furthermore, the effect of the ECAP processing temperature on microstructural evolution and mechanical properties was investigated.

\section{Materials and Methods}

\subsection{Finite Element Method}

Finite element (FE) analysis was carried out to simulate the strain and stress distribution along the sample's longitudinal and transverse sections during ECAP processing. In addition, the FE analysis was compared to the experimental geometries in order to investigate the effects of the geometric, material and process parameters on the plastic deformation behavior of pure $\mathrm{Cu}$ rods during the ECAP process. The ECAP process was modeled at RT to fully utilize the grain refinement effect and strain hardening results. To simulate the ECAP process, the cold forming extrusion module was used. The model consisted of the plunger, the ECAP die that consists of two halves, and the ECAPed rods. For clarity and improved visualization, all parts were invisible apart from the $\mathrm{Cu}$ samples during simulation. The 2-half die, and the plunger were modeled as discrete rigid elements made of an imaginary non-formable material whereas the $\mathrm{Cu}$ rod was modeled as a deformable object. The dimensions of the die and work-piece were the same as the experimental values. Pure $\mathrm{Cu}$ was selected from the ANSYS software (19.1, ANSYS Inc., Canonsburg, PA, USA) built-in library as the material of the work-piece and its mechanical and thermal properties were pre-described. Furthermore, hexahedral mesh, which is typically used in computational modeling of 3-dimensional (3D) regular shapes, was used with a mesh size of $0.5 \mathrm{~mm}$. This gave a total number of nodes ranging from 9500 to 15,000 elements depending on specimen's degree of distortion and in accordance with the mesh sensitivity analysis. The ECAPed material was modeled both as an isotropic linear elastic material and as a strain hardenable rigid plastic material. Tracked elements were located at specified regions on the plane in the middle of the specimen. The regions chosen were at the edge where max strain occurs and at the center where SPD has the lowest effect. Ram speed was chosen to be $0.15 \mathrm{~mm} / \mathrm{s}$, which equal the ram speed used experimentally. In previous studies [41,44], the coefficient of friction of $\mu=0.05-0.1$ showed good results. Therefore, the Coulomb's friction model was used with die friction factor 0.07 in this study. As an added measure due to deformation, a remeshing criterion was set to take into consideration any changes in the geometry and dimensions of the rod processing. Remeshing criteria were used based on a strain change of $0.1 \mathrm{~mm}$ and an element size of $1 \mathrm{~mm}$.

\subsection{Experimental Procedure}

Experiments were carried out on a commercial pure Cu billets (99.9\% in mass), which were received in the form of rolled billets with a $20 \mathrm{~mm}$ diameter and length of $50 \mathrm{~cm}$. 
The $\mathrm{Cu}$ billets were sectioned and machined using high precision cutting machine and a lathe to form ECAP samples with a diameter of $20 \mathrm{~mm}$ and a length of $70 \mathrm{~mm}$. The billets were annealed at $500{ }^{\circ} \mathrm{C}$ for $1 \mathrm{~h}$ under an inert atmosphere before ECAP processing followed by furnace cooling to attain an initial homogenous and fully recrystallized starting microstructure with average grain size $5.14 \mu \mathrm{m}$ and hardness of $55 \mathrm{HV}$. Cu rods were processed through ECAP for 1, 2 and 4 passes through route Bc (with the sample being rotated $90^{\circ}$ along its longitudinal axis in the same direction after each pass) at RT with a ram speed of $0.15 \mathrm{~mm} / \mathrm{s}$. To investigate the effect of processing temperature, another ECAPed sample was processed for 1 and 4 passes using route $\mathrm{Bc}$ at $200{ }^{\circ} \mathrm{C}$ to enhance dynamic recrystallization during the processes and to create possible high-angle grain boundaries (HAGBs). A graphite-based lubricant was applied to reduce the friction between the ECAPed samples and the die's inner walls before each pass. The ECAP process was performed using a split die shown in Figure 1 in which the two parts of the channel intersected with an internal channel angle of $\varphi=120^{\circ}$ and with an additional outer corner angle of $\psi=20^{\circ}$. The die geometry imposed an equivalent strain of about 0.65 per pass according to Equation (1).

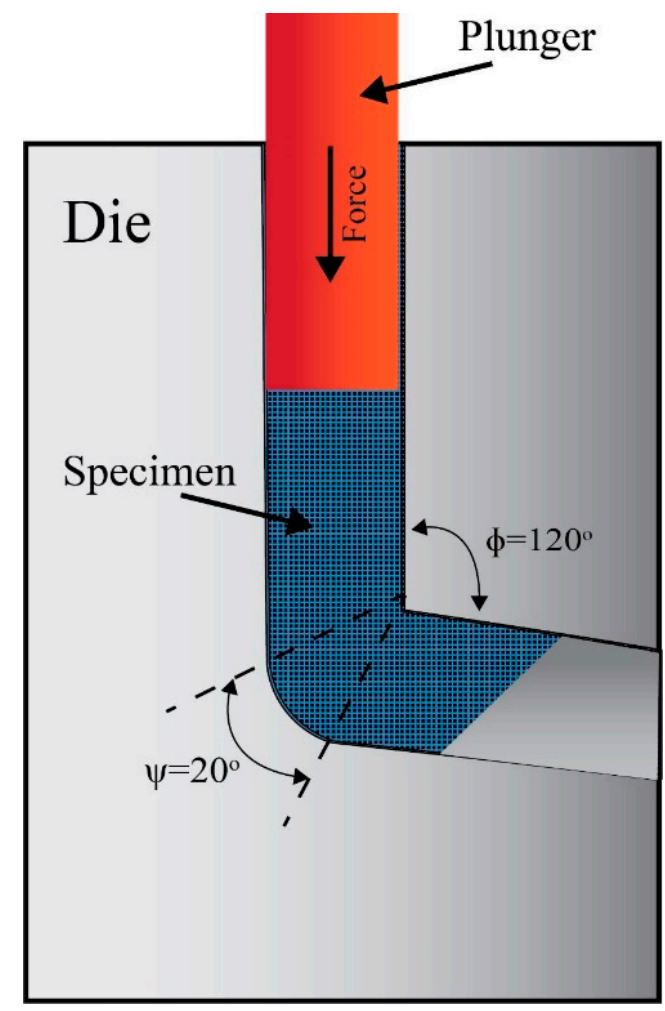

(a)

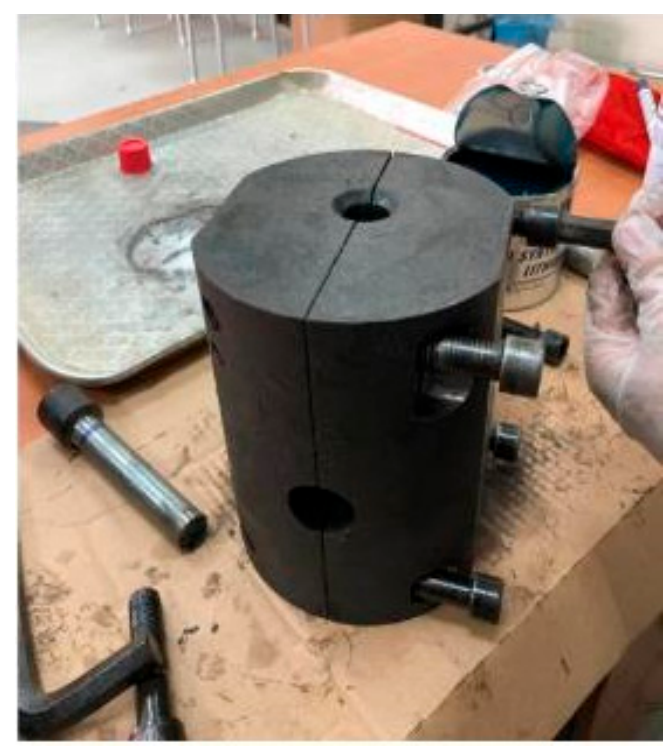

(b)

Figure 1. (a) Schematic of the right half ECAP die and (b) picture of the assembled die.

The billets before and after the ECAP process were sectioned along the central longitudinal lines parallel and perpendicular to the extrusion direction, and then grinded and polished to a mirror-like surface. Vicker's microhardness tests (HV) were conducted on the sample. Microhardness values were measured by taking readings following a rectilinear grid pattern with the spacing of $1 \mathrm{~mm}$ between each separate indentation starting at the billets' peripheries and moving towards the center on sections that were cut near the top part of the ECAPed samples. This was conducted on both parallel and perpendicular sections to the extrusion direction to evaluate the hardness variation across the ECAPed rods' longitudinal and transverse sections (LS and TS). The LS was of a square area with dimensions $20 \times 20 \mathrm{~mm}^{2}$, whereas the TS was of a circular area with $20 \mathrm{~mm}$ diameter. Both the longitudinal and transverse sections were cut near the upper part of the ECAP 
processed billets. The hardness test was carried out under an applied load of $1 \mathrm{~kg}$ for $15 \mathrm{~s}$. The displayed results were averaged over a minimum of 5 equispaced indentations. Additionally, the hardness profiles and their degrees of homogeneity were illustrated by color-coded outlines created to display the hardness distribution along the LS and TS of the ECAPed samples.

Tensile tests were performed on a $100 \mathrm{kN}$ universal testing machine (Instron 4210, Norwood, MA, USA) at RT with at a constant strain rate of $10^{-3} \mathrm{~s}^{-1}$. The tensile samples were prepared according to the specifications set by the American Society for Testing of Materials (E8M/ASTM). All the tensile samples were machined from the center of the ECAPed samples. To ensure an accurate display of the results, two tensile specimens were tested per processing.

Microstructural evolution of the rods before and after ECAP was characterized using a field emission scanning electron microscopy (FESEM) (Hitachi, Ltd., Tokyo, Japan), which equipped a NordlysMax2 EBSD detector. ECAPed rods preparation sequence was as follows: mounting the samples, followed by sample grinding, adequate polishing using alumina solution, and finally etching using a mixture of $\mathrm{HCl}$ and $\mathrm{HNO}_{3}$ solutions with a volume ratio of 3:1 as a final preparation step.

In addition, EBSD was used to investigate the structural evolution and crystallographic texture of the $\mathrm{Cu}$-rods processed with multiple passes via ECAP. Figure 2a depicts references axes with respect to the ECAPed process. Samples for microstructural characterization (EBSD) were cut from the center of the ECAP samples along their longitudinal cross-section on the plane parallel to the pressing direction (flow plane) and perpendicular to the entry channel of the die, as described in Figure 2, where the axes of the reference system coincide with the extrusion ECAP direction " $Y$ " (ED), the normal direction " $Z$ " (ND) and the transversal direction " $X$ " (TD). The investigated specimens were grinded and mechanically polished with a tripod polisher down to $1 \mu \mathrm{m}$ diamond particle. A final chemical-mechanically polishing with $0.05 \mu \mathrm{m}$ colloidal silica was performed for $12 \mathrm{~h}$ with a BUEHLER Vibrometer. The EBSD measurements were performed on the top surface TD-ED plan as indicated by a red rectangle on Figure $2 b$ using a Hitachi SU-70 SEM operating at $15 \mathrm{kV}$ and at a typical current of $1.5 \mathrm{nA}$. Crystallographic orientation maps were obtained using HKL Channel 5 acquisition system of oxford instruments. To achieve good statistical data due to the presence of coarser grains, a larger scan area was selected for as-annealed and processed samples. The EBSD scans were in areas of $127 \mu \mathrm{m} \times 95 \mu \mathrm{m}$ with $0.2 \mu \mathrm{m}$ step size. In order to minimize the measurements error and the deformation induced by the preparation stage, misorientations below $3^{\circ}$ were not considered in the post-processing data procedure. Additionally, low angle grain boundaries (LAGBs) were defined as misorientation angles between $3^{\circ}$ and $15^{\circ}$ and presented in white lines on the band contrast maps, while the high-angle grain boundaries (HAGB) were defined when misorientation angles were greater than $15^{\circ}$ and presented in black lines on the band contrast maps. Certainly, all grains in the outer frame of each region of interest were excluded. In Table 1, the total number of grains and number of grains after excluding the border grains and grains less than 4 pixels.

Table 1. The average grain size of the commercial purity $\mathrm{Cu}$ processed through ECAP up to 4-Bc.

\begin{tabular}{|c|c|c|c|c|c|c|}
\hline Condition & $\begin{array}{l}\text { Average Grain } \\
\text { Size }(\mu \mathrm{m})\end{array}$ & $\begin{array}{c}\text { Standard } \\
\text { Deviation }(\mu \mathrm{m})\end{array}$ & $\begin{array}{l}\text { Min Grain } \\
\text { Size }(\mu \mathrm{m})\end{array}$ & $\begin{array}{c}\text { Max Grain } \\
\text { Size }(\mu \mathrm{m})\end{array}$ & $\begin{array}{l}\text { Total Number } \\
\text { of Grains }\end{array}$ & $\begin{array}{c}\text { Number of } \\
\text { Subtotal Grains } N\end{array}$ \\
\hline $\mathrm{AA}$ & 5.1 & 3.7 & 0.2 & 27.2 & 688 & 324 \\
\hline 1-P-RT & 3.9 & 2.0 & 0.6 & 25.5 & 914 & 520 \\
\hline 2-Bc-RT & 3 & 2.5 & 1.2 & 24.0 & 2004 & 854 \\
\hline 4-Bc-RT & 3.5 & 3.0 & 1.2 & 24.0 & 1486 & 588 \\
\hline $1-\mathrm{P}-200{ }^{\circ} \mathrm{C}$ & 4.4 & 3.4 & 1.2 & 21.7 & 765 & 379 \\
\hline $4-\mathrm{Bc}-200^{\circ} \mathrm{C}$ & 2.5 & 1.7 & 1.2 & 15.5 & 3669 & 1217 \\
\hline
\end{tabular}


(a)

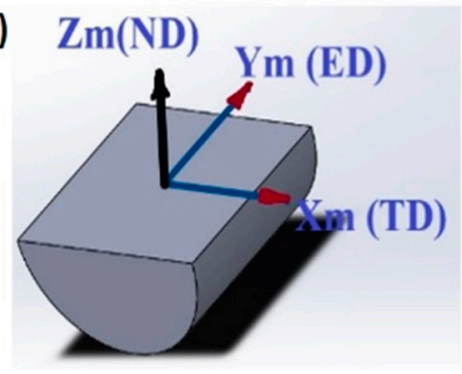

(b)

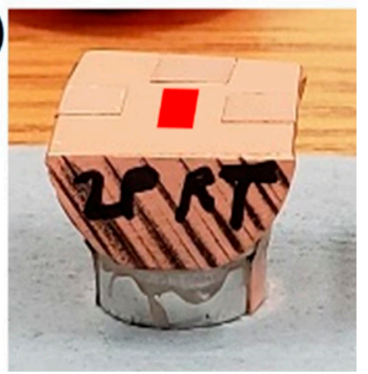

Figure 2. (a) Representation of the references axes with respect to the ECAPed sample and (b) the position of the EBSD data acquired shown as red square on the longitudinal cross section of the ECAP processed sample.

\section{Results}

\subsection{Finite Element Analysis}

Color contour maps showing the distribution of the stress and plastic strains in the longitudinal section of the simulated $\mathrm{Cu}$ sample after processing through 1-pass (1-P) of ECAP at RT are illustrated in Figures 3 and 4, respectively. The plunger and die have been removed for better visualization. As evident in Figures 3 and 4, the maximum stresses and strains are present at the corner and peripheral areas. This surge compared to the central areas occurs as the peripheral regions were in contact with the die's walls. In addition, Figures 3 and 4 revealed a slight increase in the stress and imposed strain at the top part of the sample compared to the bottom part due to the contact with the die channel angel. Accordingly, this finding agreed with Deng et al. [41]. On the other hand, the lower part of the ECAPed processed samples revealed lower effective strain as compared to the upper part due to imposing a combination of bending and shear mechanisms as depicted in Figure 4.

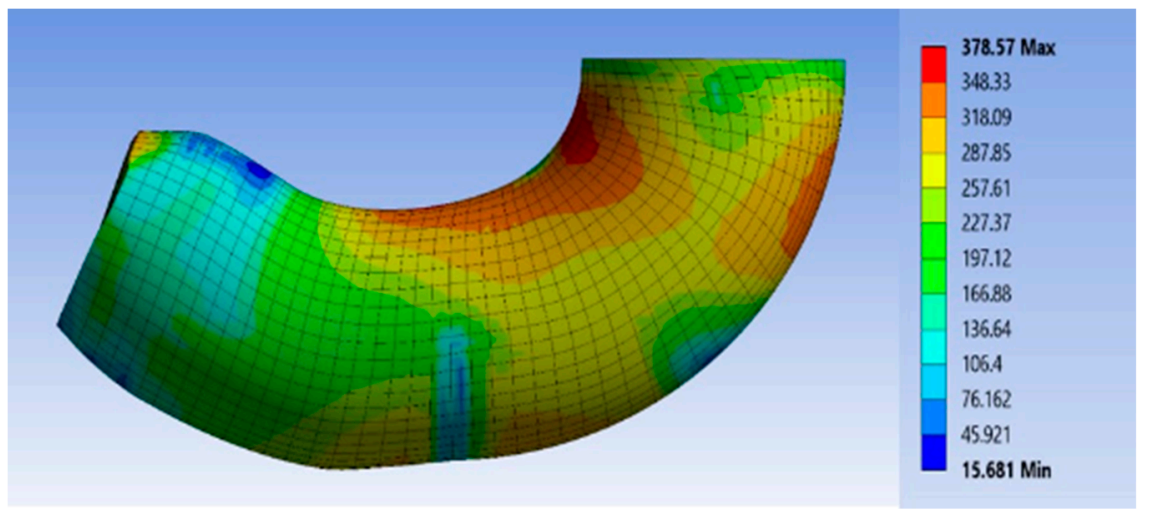

Figure 3. Simulation of effective stresses distribution in $\mathrm{Cu}$ samples processed through 1-P at room temperature.

Figure 3 shows the processed rod after being processed via 1-P, where the maximum stress experienced was in the range of $379 \mathrm{MPa}$, which occurred in the peripheral regions. On the other hand, the bottom central region experienced lower stresses of $106 \mathrm{MPa}$, which confirms the distribution obtained in an earlier study [45]. Moreover, it can be observed that the upper part of the ECAPed billet experienced higher stresses (227 MPa) compared to the lower part $(15.7 \mathrm{MPa})$ as a result of the direct contact between the top ends with the plunger. A similar trend was displayed for the strain distribution as shown in Figure 4 whereas, ECAP processing via 1-P displayed a max effective strain of 0.74 , which was depicted in the upper peripheral region, which indicates considerable agreement with the results obtained from the analytical calculations using Equation (1). On the other hand, the lower central region encountered a minimum effective strain of 0.15 , which matches 
with the stress distribution showed in Figure 3. Similar strain distribution patterns were noted in some earlier studies $[46,47]$. The increase in the effective plastic strain from the bottom to the top can be explained by the formation of the corner gap. As the bottom part of the ECAPed sample was no longer in contact with the die. Consequently, lower degree of deformation occurred in the bottom of the sample [4]. Accordingly, this inconsistency in the stresses and plastic strain values recorded along the LS of the ECAP sample will significantly affect the homogeneity in the mechanical properties and microstructural features throughout the sample.

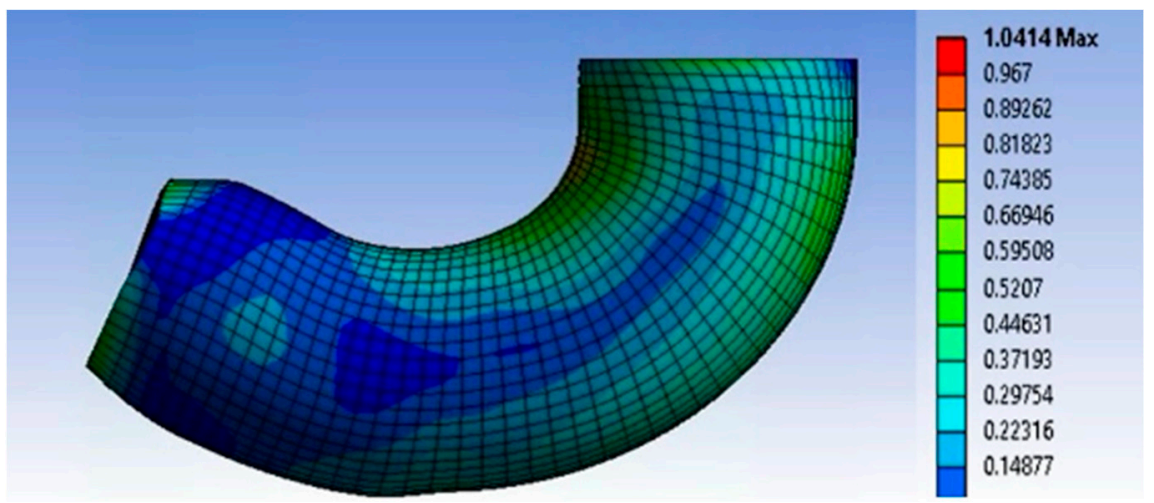

Figure 4. Simulation of effective strain distribution after processing through 1-P.

\subsection{Grain Structure and Crystallographic Texture}

Figure 5 shows the inverse pole figure (IPF) coloring map where the grains are oriented with their 111 along the normal direction ND for the as annealed with its corresponding band contrast (BC) map with the high angle grain boundaries (HAGBs) of a misorientation angle above $15^{\circ}$ are outlined as black lines and low angle grain boundaries (LAGBs) of misorientation between $3^{\circ}$ and $15^{\circ}$ are depicted in white lines. The IPF microstructure of the as annealed $\mathrm{Cu}$ (Figure 5a) consists of almost equiaxed grains. In addition, several twins are present within the as-annealing microstructure with an average grain size of $5.1 \pm 3.7 \mu \mathrm{m}$ including twins based on EBSD data with twin boundary criteria of 60 deg or less. However, the size distribution was heterogeneous through the as-annealing microstructure, and some finer grains down to $5 \mu \mathrm{m}$ were visible between the coarse grains up to $27 \mu \mathrm{m}$. The grain boundary map in Figure 5b indicates that the map was dominated by HAGBs and almost free of the LAGBs, which implies that the microstructure was fully recrystallized.

Figure 6 shows three and their corresponding BC maps with the HAGBs $>15^{\circ}$ in black lines and $15^{\circ}>$ low angle grain boundaries (LAGBs) $>3^{\circ}$ superimposed for the 1-P ECAP processed pure $\mathrm{Cu}$ at RT obtained at the two edges $(\mathrm{a}, \mathrm{c})$ and at the center $(\mathrm{b})$ of the sample LS. It can be observed that the microstructure consists of a mixture of many relatively fine and few relatively coarse grains that can be considered a type bimodal microstructure. This can be observed across the whole cross section with notable increase in the density of the LAGBs relative to the as-annealed (AA) material. In addition, a microstructure exhibiting a smaller average grain size of $3.9 \pm 2.0 \mu \mathrm{m}$ with a high density of twins can be observed. The reduction in the average grain size can be attributed to the formation of new HAGBs due to the high amount of strain experienced during the first pass. The effective strain after the 1-P estimated by the numerical modeling above to be about 0.74 at the peripheral of the billet. $\mathrm{Cu}$ is a medium stacking fault energy $(\gamma \mathrm{SFE}) \mathrm{fcc}$ metal of about $80 \mathrm{~mJ} / \mathrm{m}^{2}$ [48]. The amount of energy stored in the material due to plastic deformation is about $1 \%$ of the work done during plastic deformation and about $99 \%$ is dissipated as heat [49]. Thus, this condition can lead to partial recrystallization especially the recrystallization temperature of pure $\mathrm{Cu}$ is about $180^{\circ} \mathrm{C}$ [49]. 

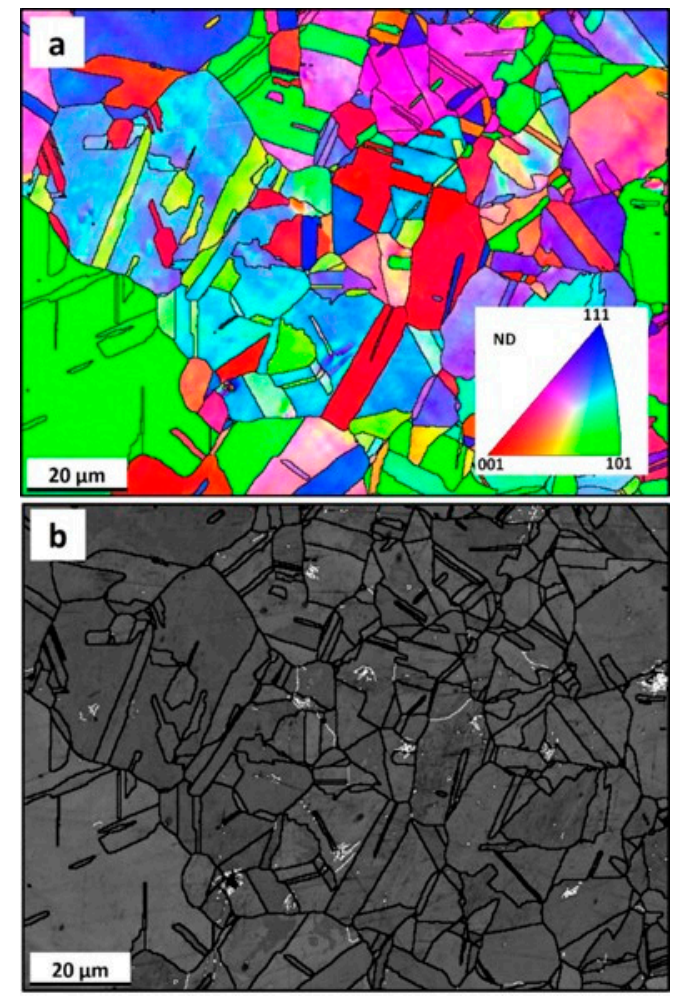

Figure 5. (a) Inverse pole figure (IPF) coloring maps and (b) band contrast maps with the angle boundaries superimposed for as annealed pure Cu. IPF coloring triangle is shown in (a), red: [001]; blue; [111] and green: [101] (for interpretation of the references to color in this figure legend, the reader is referred to the web version of the article).
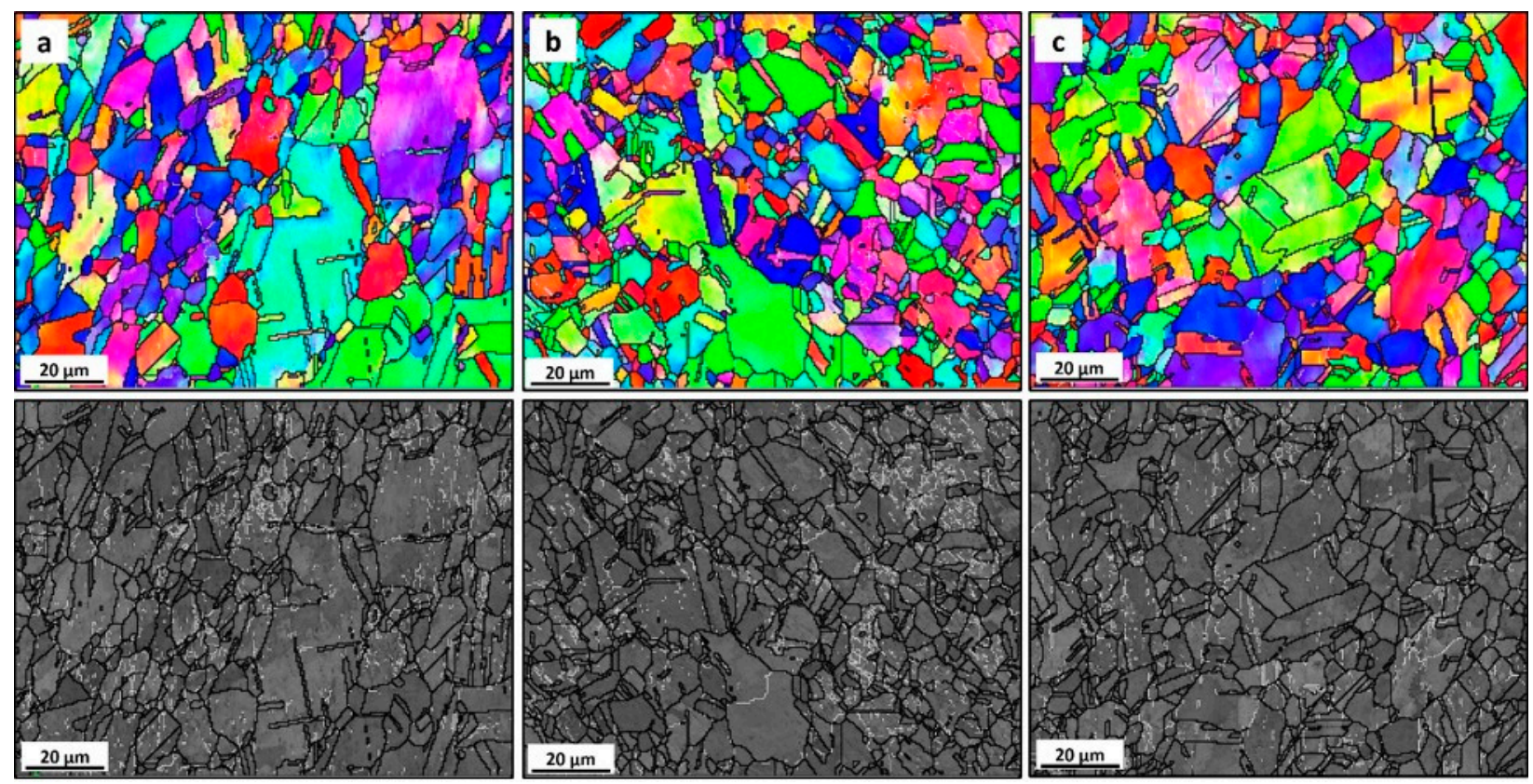

Figure 6. IPF coloring maps relative to normal direction " $\mathrm{Z}$ " (ND) and their corresponding band contrast maps with the angle boundaries superimposed for the commercial pure Cu ECAP processed at room temperature (RT) for 1-P. (a) Left edge, (b) center and (c) right edge. Step size used in EBSD data collection was $0.5 \mu \mathrm{m}$ in all cases (for interpretation of the references to color in this figure legend, the reader is referred to the web version of the article). 
Figure 7 shows the IPF maps and their corresponding BC maps with the HAGBs and LAGBs superimposed for the 2 passes (2-Bc) (a) and 4 passes (4-Bc) (b) ECAP processed pure $\mathrm{Cu}$ at RT. It can be observed that the density of the LAGBs increased significantly due to the strain accumulation after 2-Bc and 4-Bc passes. The average grain size after 2-BC and $4-\mathrm{Bc}$ was also reduced to $3 \pm 2.5 \mu \mathrm{m}$ and $3.5 \pm 3.0 \mu \mathrm{m}$, respectively. The 2-Bc passes and $4-\mathrm{Bc}$ passes led to an increase in the amount of the substructure without any effect in grain coarsening. It was also observed that the UFG at RT were locally heterogeneous up to the second pass, but further deformation enhanced the homogeneity of grain size distribution. These obtained results were in good agreement with the reported $[40,50]$. Higuera-Cobos and Cabrera [50] studied the microstructure of pure $\mathrm{Cu}$ after ECAP processing with the starting annealed equiaxed grain structure of a grain size average of about $5.5 \mu \mathrm{m}$. They reported that the microstructure after the 1-P consists of elongated grains with well-developed substructure while after 4,8 and 16 passes they reported saturated microstructure after the fifth pass that is a heterogeneous microstructure of large grains with ultrafine grains. Zhu et al. [40] studied the microstructure of pure $\mathrm{Cu}$ after ECAP with starting extremely large grains of $410 \mu \mathrm{m}$. They reported grain refining to about $210 \mu \mathrm{m}$ after 4 passes. Then increasing the passes to 8-P resulted in the formation of dislocation cells with a size of $500 \mathrm{~nm}$ up to $3 \mu \mathrm{m}$.

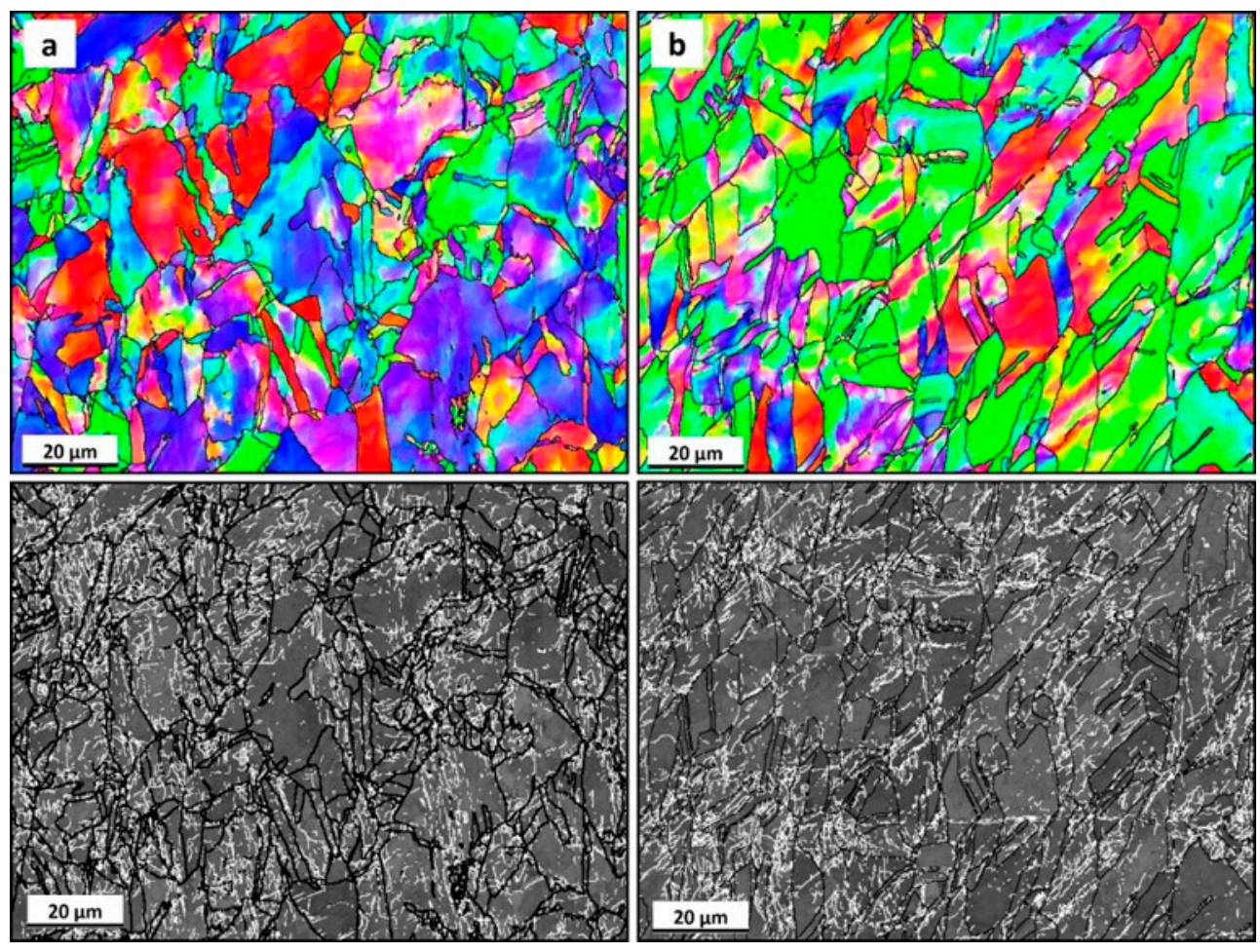

Figure 7. IPF coloring maps relative to ND and their corresponding band contrast maps with the angle boundaries superimposed for the commercial pure $\mathrm{Cu}$ ECAP processed at RT for (a) 2-P and (b) 4-Bc. Step size used in EBSD data collection was $0.2 \mu \mathrm{m}$ in all cases (for interpretation of the references to color in this figure legend, the reader is referred to the web version of the article).

The ECAP process also was carried out at temperature of $200^{\circ} \mathrm{C}$ for 1-P and 4-Bc to study the effect of temperature on the microstructural evolution. Figure 8 shows the IPF coloring maps relative to the ND and the $\mathrm{BC}$ maps with the HAGBs $>15^{\circ}$ misorientation in black lines and LAGBs $<15^{\circ}$ misorientation in white lines for the ECAP processed pure $\mathrm{Cu}$ at $200{ }^{\circ} \mathrm{C}$ for 1-P and 4-Bc. It can be observed that the grains after 1-P were elongated with notable amount of LAGBs. Increasing the number passes to $4-\mathrm{Bc}$ resulted in a significant increase in the density of the LAGBs with a clear reduction in the average grain size. The average grain size after 1-P and $4-B c$ was $4.3 \pm 3.4 \mu \mathrm{m}$ and $2.5 \pm 1.7 \mu \mathrm{m}$, respectively. 
The grain morphology indicates the heavy deformation that experienced and resulted in distorted grains after 1-P and more severely after 4-Bc. It is quite possible that the main features of the microstructure formed at $200{ }^{\circ} \mathrm{C}$ in regime 2 were similar to that formed at $\mathrm{RT}$ in regime 1 . However, the amount of elongated grains decreased with increasing the deformation temperature and sharp boundaries became more evident at $200{ }^{\circ} \mathrm{C}$. The average grain size summarized from the EBSD characterization are shown in Table 1 for the AA, 1-P, 2-Bc, 4-Bc, 1-P-200 ${ }^{\circ} \mathrm{C}$ and $4-\mathrm{P}-200{ }^{\circ} \mathrm{C}$ samples.
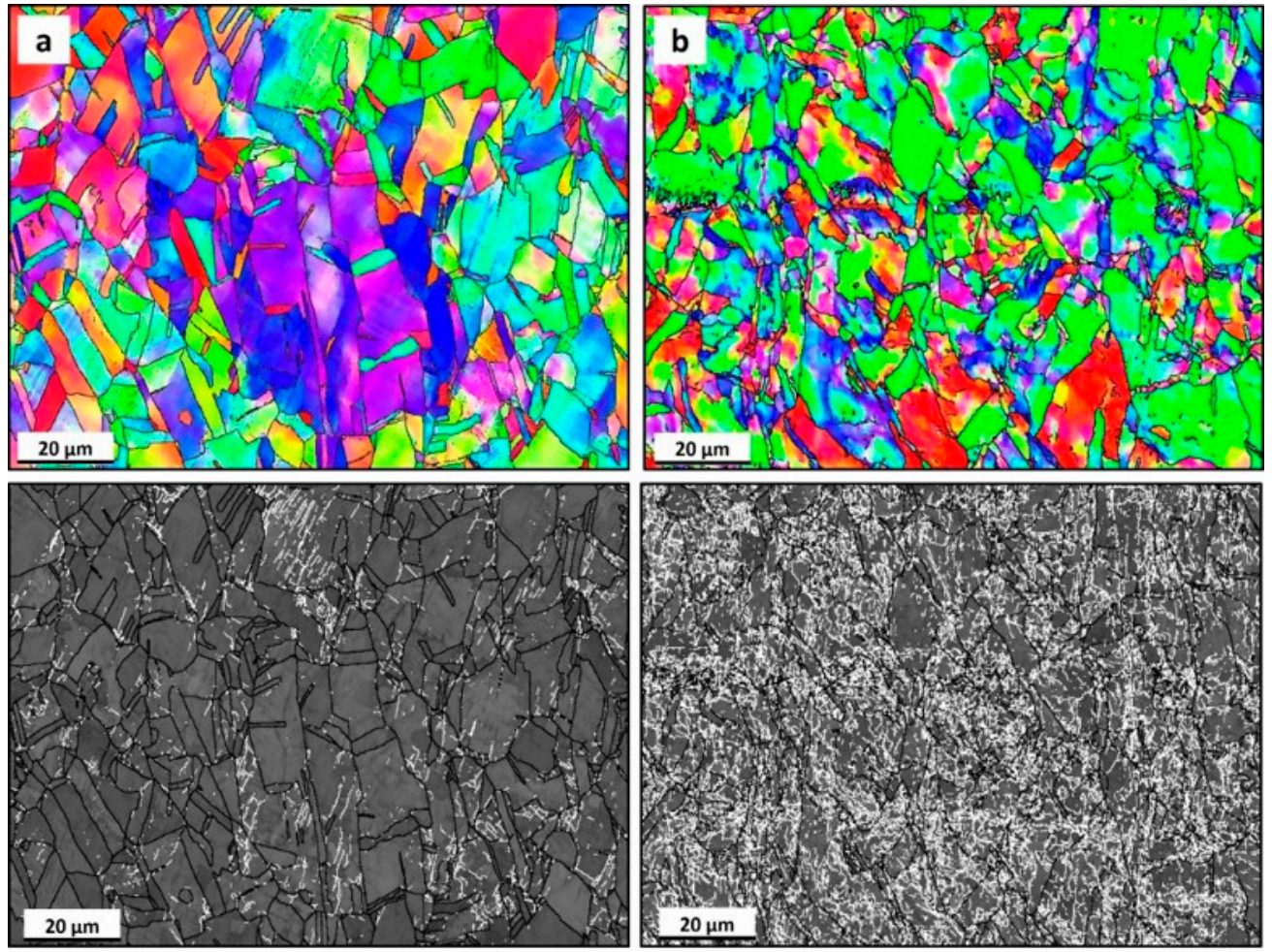

Figure 8. IPF coloring maps relative to ND and their corresponding band contrast maps with the angle boundaries superimposed for the commercial pure Cu ECAP processed at $200{ }^{\circ} \mathrm{C}$ for (a) 1-P and (b) 4-Bc Step size used in EBSD data collection was $0.2 \mu \mathrm{m}$ in all cases (for interpretation of the references to color in this figure legend, the reader is referred to the web version of the article).

Figure 9 shows the (110) and (111) pole figures of the AA and ECAP processed pure $\mathrm{Cu}$ at RT and at $200{ }^{\circ} \mathrm{C}$. As can be seen from Figure 9a, the as annealed Cu showed high intensity texture of about 7 times random, which could be directly related to the previous processing history of the billet. This strong texture was completely transformed after the first ECAP pass towards the simple shear texture with an intensity of about 4 times random. After 2-Bc and 4-Bc the texture completely resembled the simple shear texture with about 7 times random again. Simple shear textures of fcc metals were characterized by two partial fibers: (i) (111) $\| \mathrm{ND}$ (Shear plane) containing $\mathrm{A} / \overline{\mathrm{A}}$ and $A_{1}^{*}$ and $A_{2}^{*}$ and (ii) (110)) $\|$ I ED (shear direction) composed of $\mathrm{A} / \overline{\mathrm{A}}, \mathrm{B} / \overline{\mathrm{B}}$ and $\mathrm{C}$ as the ideal components [51,52], Table 2 lists the partial fibers and ideal simple texture components in fcc metals. From the pole figures after 2-BC and 4-Bc it can be noted that the main texture components that developed after ECAP processing are A/ $\bar{A}$ and $C$ with the miller indices of $\{111\} /<101>,\{11 \overline{0}\} /<11 \overline{0}\rangle$ and $\{001\} /<11 \overline{0}>$ respectively. These components can be observed almost at all their ideal positions in 111 and 110 pole figures after 4 -Bc with the ideal component positions superimposed in Figure 10. These texture components are reported to be developed at low temperatures and low strain [51]. Li et al. [52] investigated the texture heterogeneity after ECAP processing of pure copper via route $\mathrm{C}$ and reported that after two passes a significant variation in the crystallographic texture across the sample thickness was observed and all the textures show shear-type characteristics. This is in agreement with the texture 
characteristics observed here. Additionally, Mishin and Bowen [53] investigated the texture of ECAP processed copper and reported a strong simple shear texture after equivalent strain of 10 .
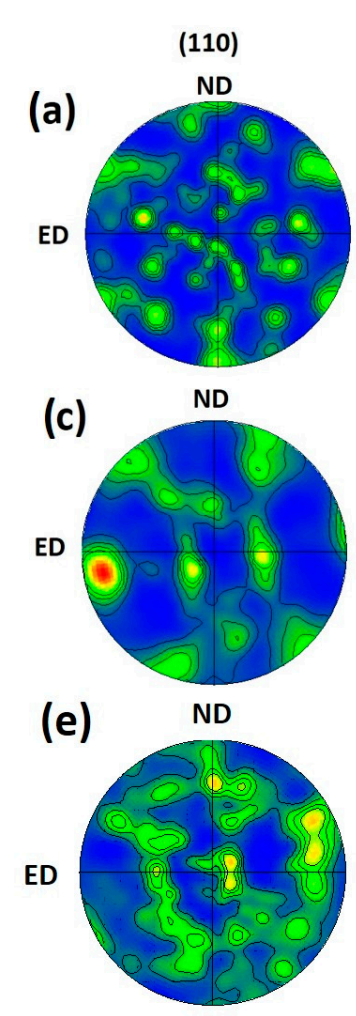

(111)
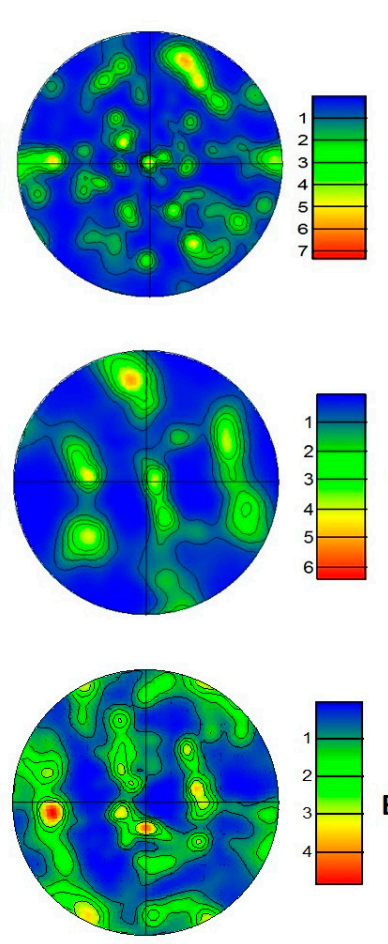

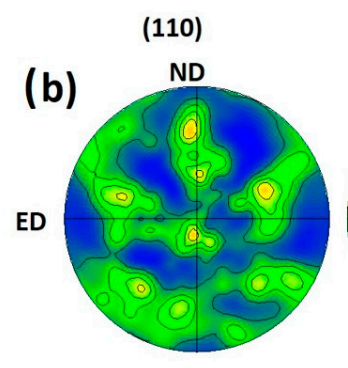

(d)

ED

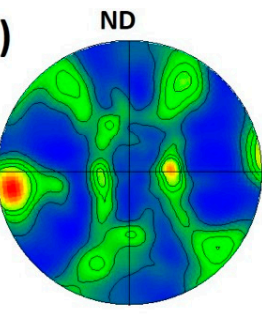

ND

(f)
(111)
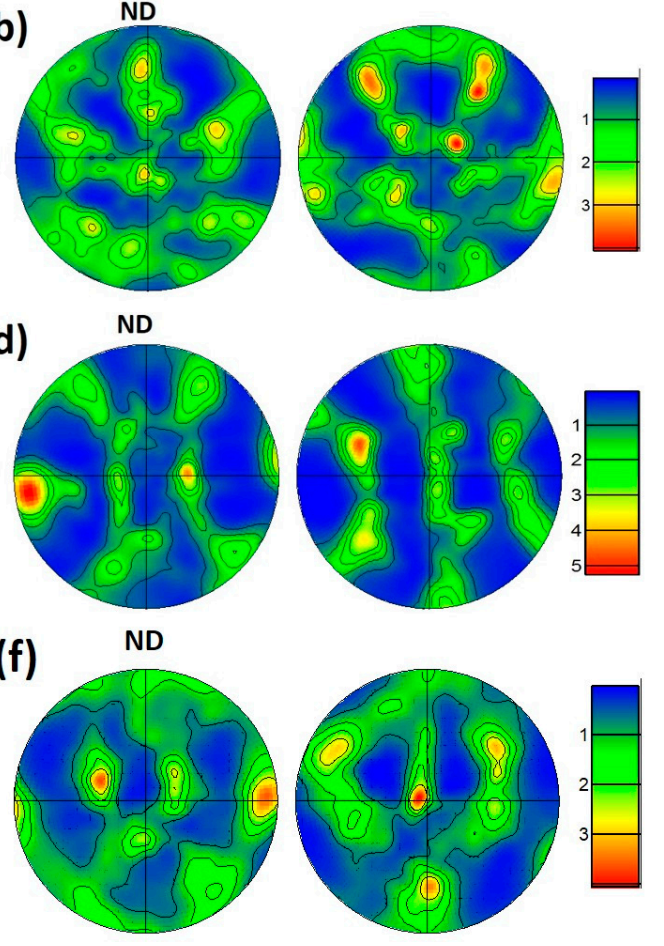

Figure 9. (110) and (111) pole figures of commercial pure Cu for the (a) AA, (b) 1-P_RT, (c) 2-Bc_RT, (d) 4-Bc_RT, (e) 1P_200 ${ }^{\circ} \mathrm{C}$ and (f) 4 -Bc_200 ${ }^{\circ} \mathrm{C}$ samples (for interpretation of the references to color in this figure legend, the reader is referred to the web version of the article).

Table 2. Partial fibers and ideal components of simple shear texture in fcc metals [45-55].

\begin{tabular}{cccc}
\hline & Partial Fibers & Shear Plane & Shear Direction \\
\hline $\begin{array}{c}\text { A fiber } \\
\text { B fiber }\end{array}$ & $\begin{array}{c}\{111\} \\
(\mathrm{hkl})\end{array}$ & $\begin{array}{c}<\text { uvw }> \\
<110>\end{array}$ \\
\hline Components & & \\
\hline A fiber & B fiber & & $\langle 2 \overline{1} 1\rangle$ \\
$\mathrm{A}_{1}^{*}$ & & $\{11 \overline{1}\}$ & $\langle 112\rangle$ \\
$\mathrm{A}_{2}^{*}$ & $\mathrm{~A}$ & $\{11 \overline{1}\}$ & $\langle 101\rangle$ \\
$\mathrm{A}$ & $\mathrm{A}$ & $\{11 \overline{1}\}$ & $\langle 1 \overline{1} 0\rangle$ \\
$\bar{A}$ & $\mathrm{~B}$ & $\{112\}$ & $\langle 1 \overline{1} 0\rangle$ \\
& & $\{\overline{112}\}$ & $\langle 1 \overline{1} 0\rangle$ \\
\hline & $\mathrm{C}$ & $\{001\}$ & \\
\hline
\end{tabular}



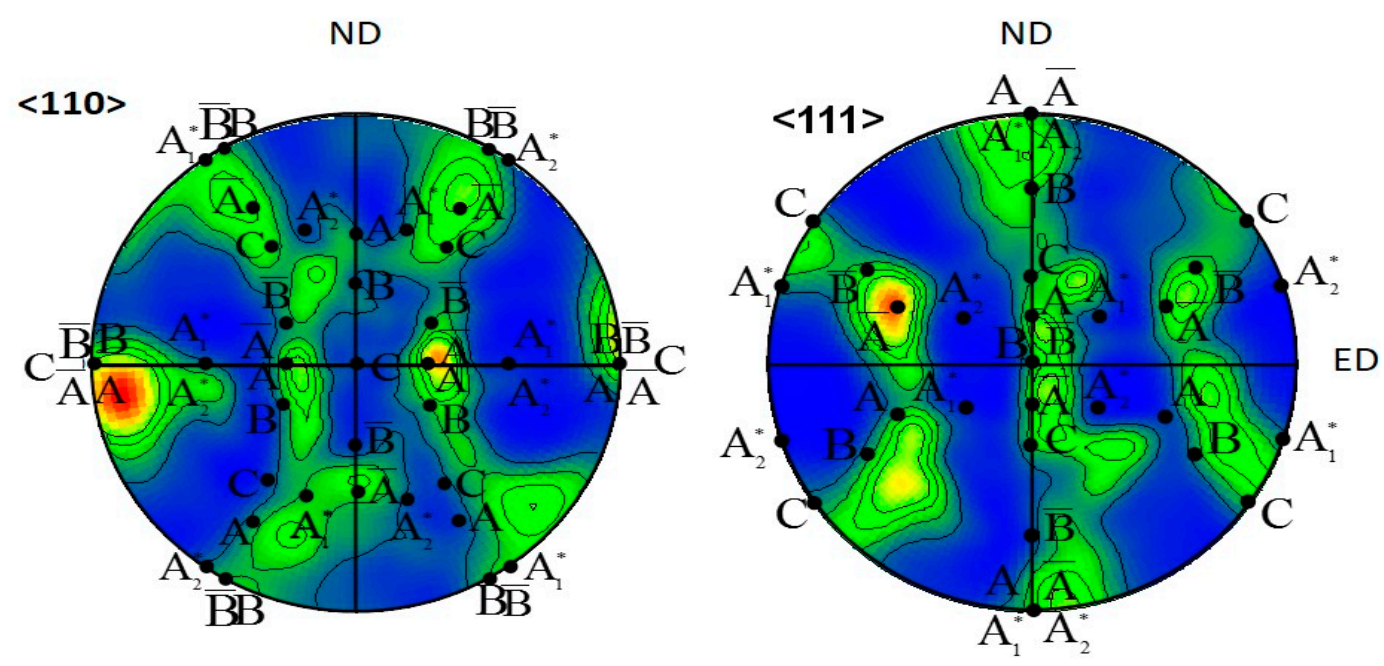

Figure 10. (111) and (110) pole figures of commercial pure $\mathrm{Cu}$ after processing through 4-Bc_RT with the ideal simple shear texture components superimposed (for interpretation of the references to color in this figure legend, the reader is referred to the web version of the article).

Figure 11 shows the grain size distribution for the as annealed $\mathrm{Cu}$ and after ECAP processed at RT (1-P, 2-Bc and 4-Bc) and at $200{ }^{\circ} \mathrm{C}$ (1-P and 4-Bc). It can be observed that the amount of UFG on the collected data was increased after the ECAP process. Figure 12 shows the misorientation angle distribution for the AA commercial pure $\mathrm{Cu}$ and after ECAP processed at RT (1-P and 4-Bc) and at $200{ }^{\circ} \mathrm{C}$ (1-P and 4-Bc). It can be noted that the amount of the LAGBs was significantly increased by the increase of the number of ECAP passes. Both the high amount of ultrafine grains and the high amount of LAGBs represent the main contributors in the significant improvement the mechanical properties after ECAP processing of commercial pure $\mathrm{Cu}$.

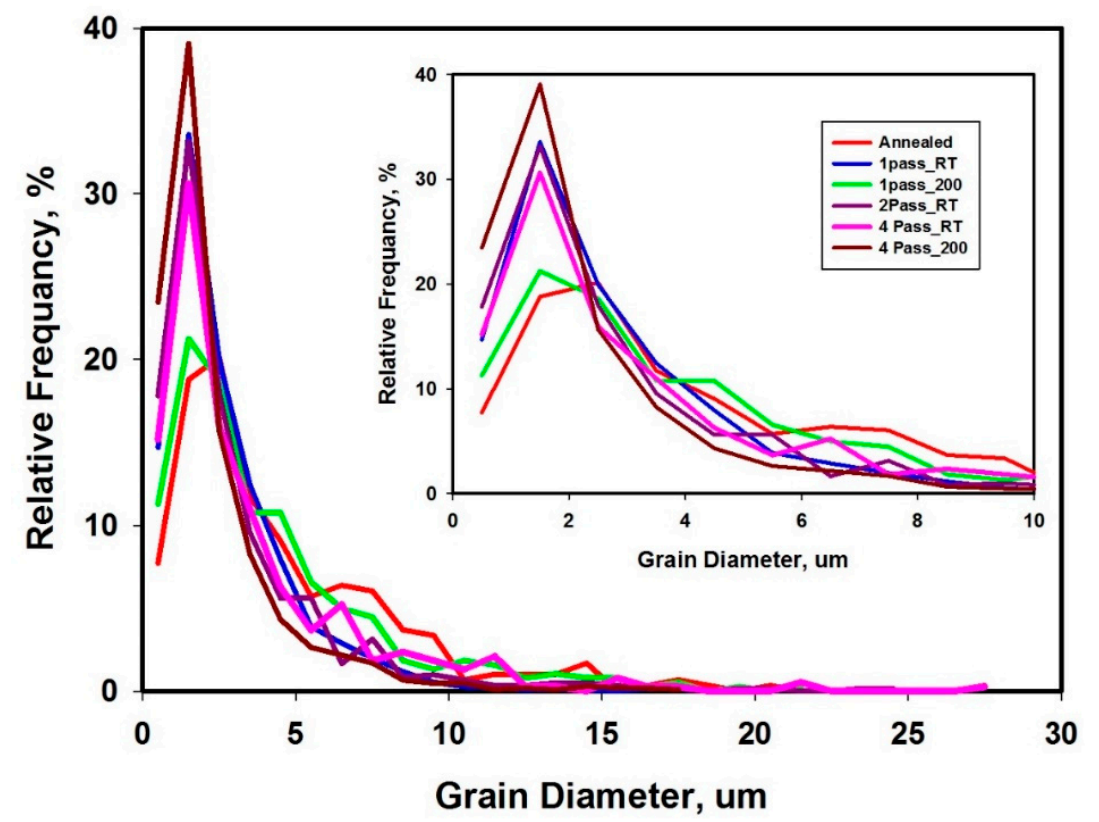

Figure 11. Relative frequency of the different grain diameters of as annealed commercial pure $\mathrm{Cu}$ and after ECAP processing through 1-P, 2-Bc and 4-Bc. 


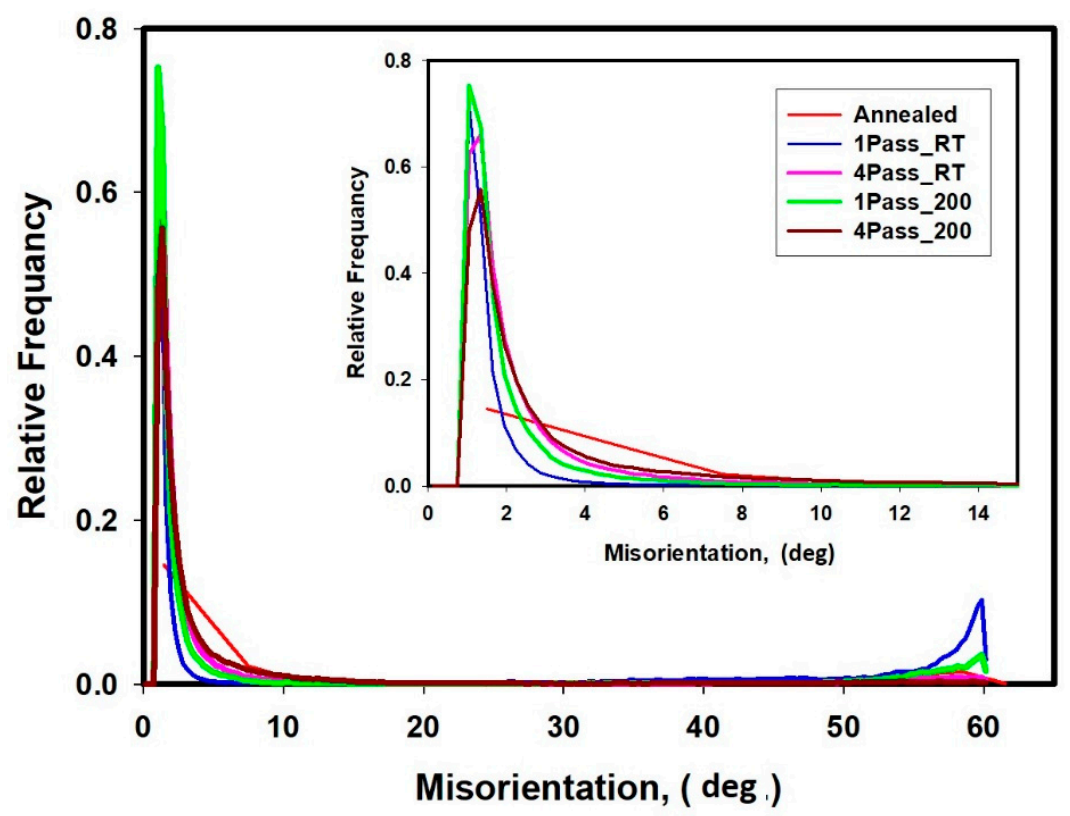

Figure 12. Relative frequency of the misorientation angle distribution of AA commercial pure $\mathrm{Cu}$ and after ECAP processing for 1-P and 4-Bc.

\subsection{Mechanical Properties}

HV evolution through the LS of the commercial pure Cu processed after 1-P, 2-Bc and 4-Bc at RT was plotted in color-codded hardness contour maps shown in Figure 13. The hardness contours of the AA samples were not displayed because they were essentially homogeneous across the whole sample with an average of $\mathrm{HV}=55$. Similar plots presented in Figure 14 displays the hardness contour maps for the TS, which revealed that the strain hardening was the highest at the corner and peripheral regions and decreased towards the central regions. From Figure 13, it can be clearly observed that there is a compelling increase in the HV after the first pass and then a slight increase with the increase of passes. These findings are in a good agreement with the earlier studies $[1,56]$. On the other hand, the first pass ECAPed samples showed the most heterogeneous structure and this behavior was lessened at the following passes. Similar behavior was revealed as shown in Figure 14 for the hardness distribution along the ECAPed samples' TS. From Figures 13 and 14, the lowest hardness values were noticed at the central region of the ECAPed sample, and then the hardness values increased radially. It is worth mentioning here that, 1-P (Figure 13a) yielded higher hardness values at the upper part of the rod when put in comparison with the lower parts, which concurred with the findings from the billets ECAPed via either 2-Bc or 4-Bc, as shown in Figure 13. This could be explained by contact with the applied pushing force from the plunger, which yielded comparably higher hardness values at the top part. Accordingly, the hardness findings in a good correlation with the FE analysis shown in Figure 4, where the maximum imposed strain were depicted in the peripheral areas resulting in more strain hardening and led to increasing the hardness compared to the central regions. 


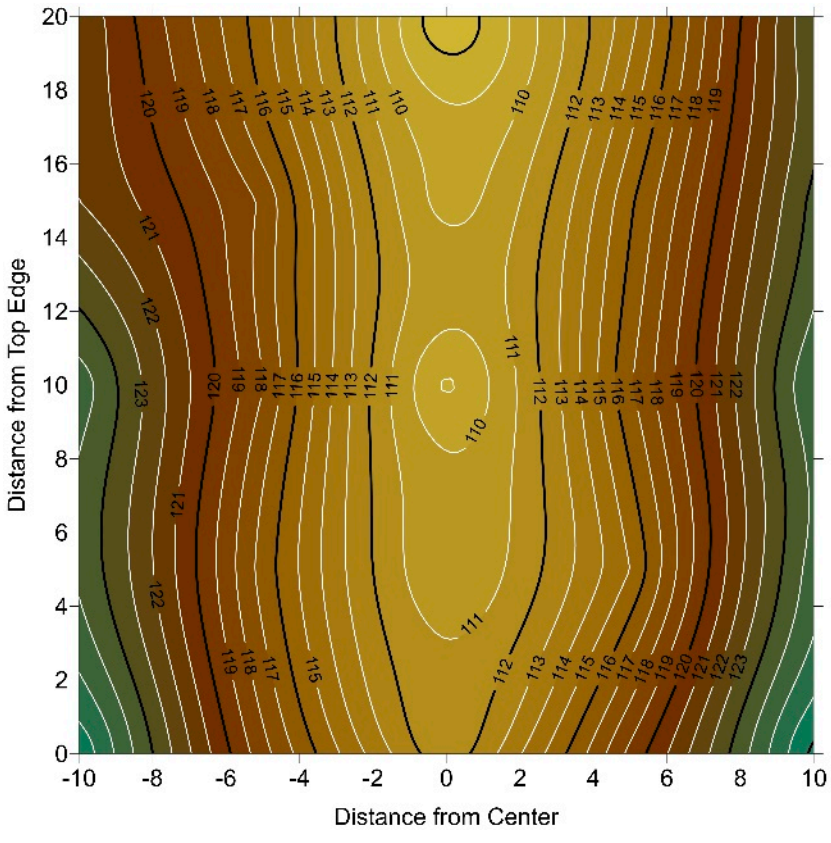

(a)

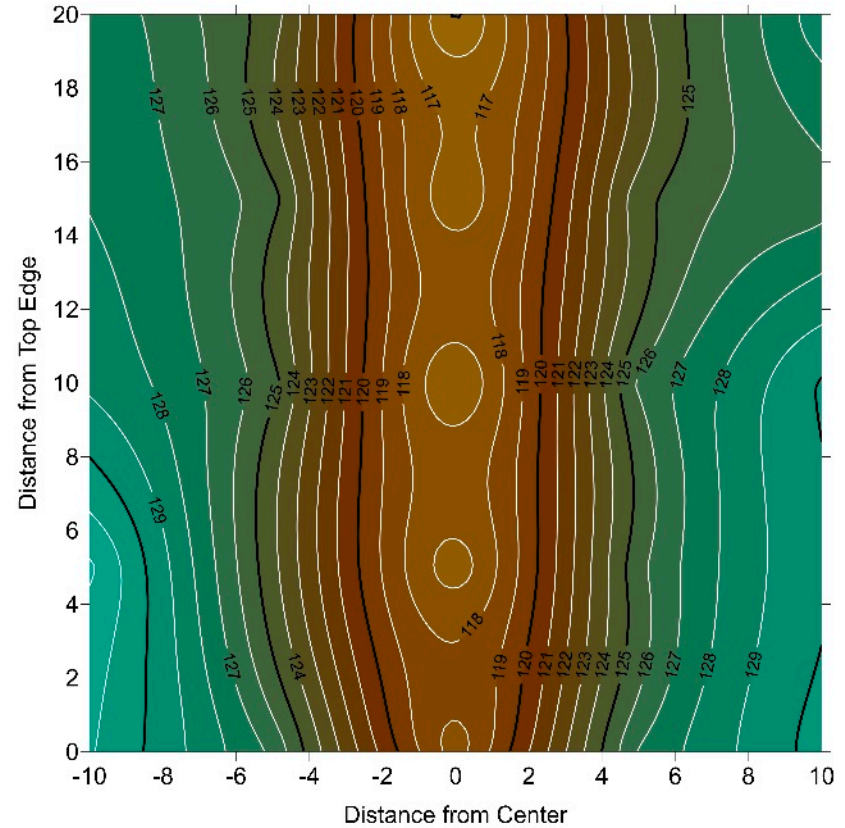

(b)

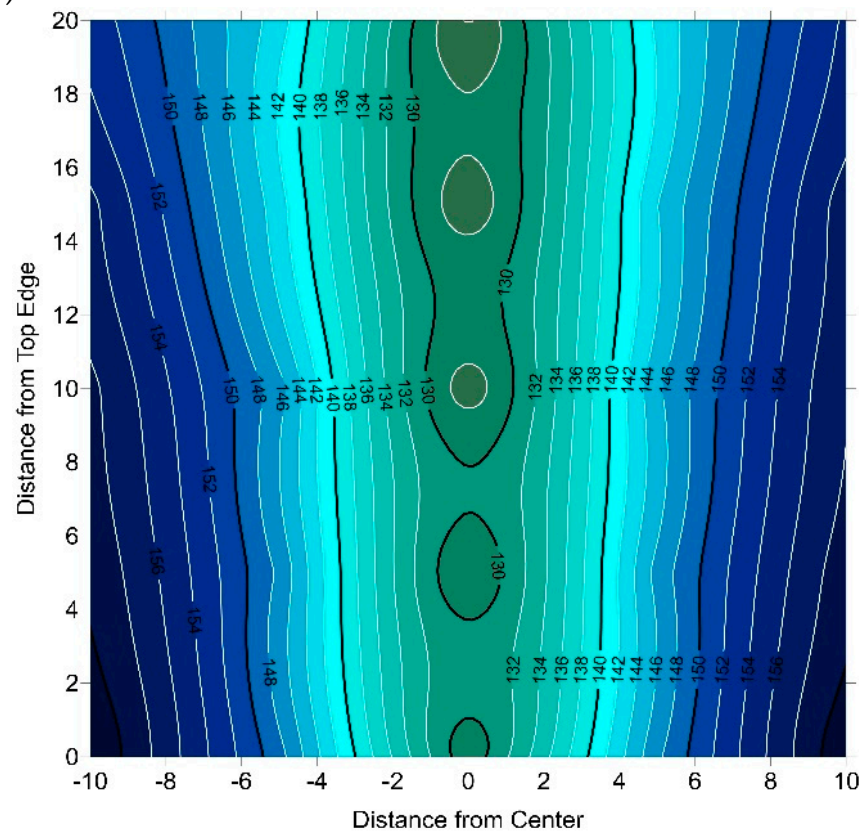

(c)

Figure 13. Color coded contour maps for the hardness (HV) values recorded on the longitudinal section (LS) of the Cu billets processed via ECAP processing after (a) 1-P, (b) 2-Bc and (c) 4-Bc. 


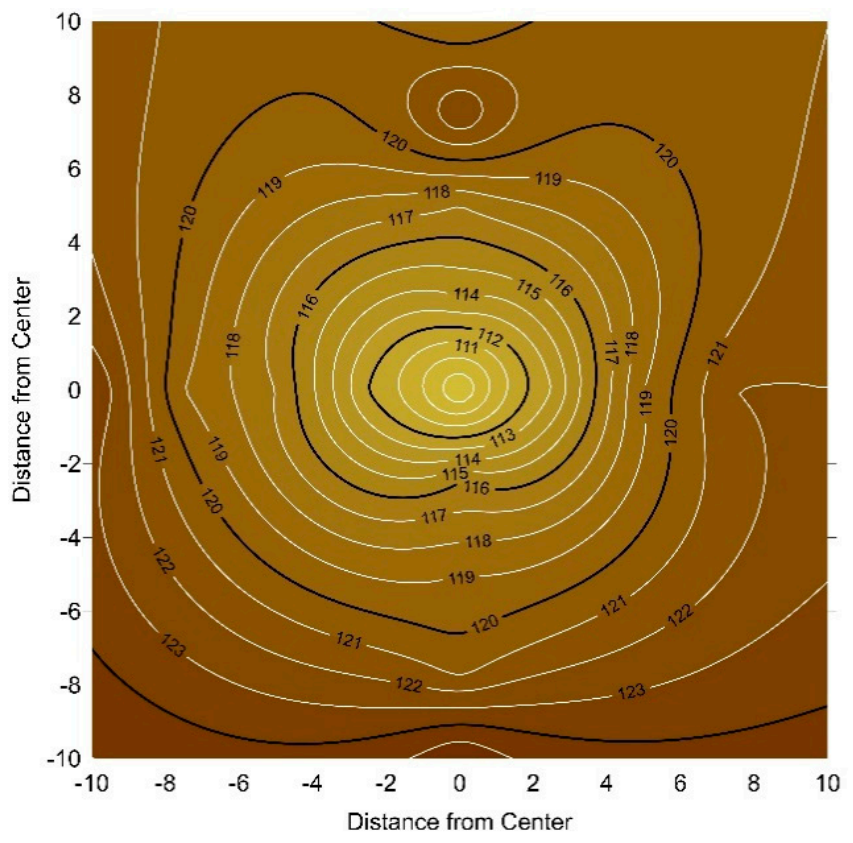

(a)

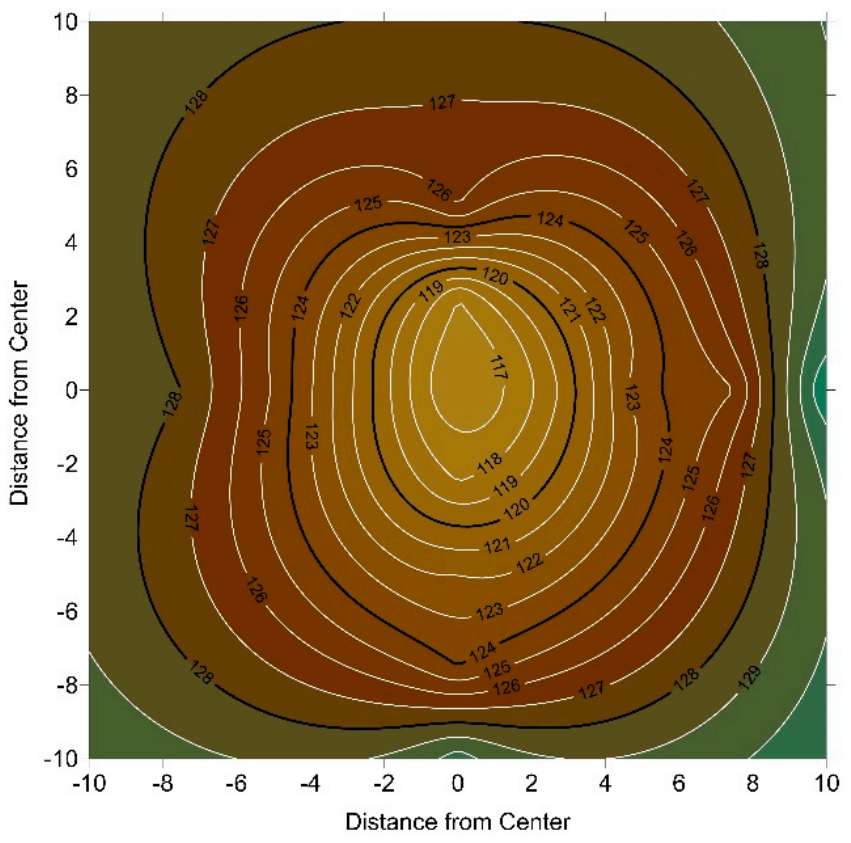

(b)

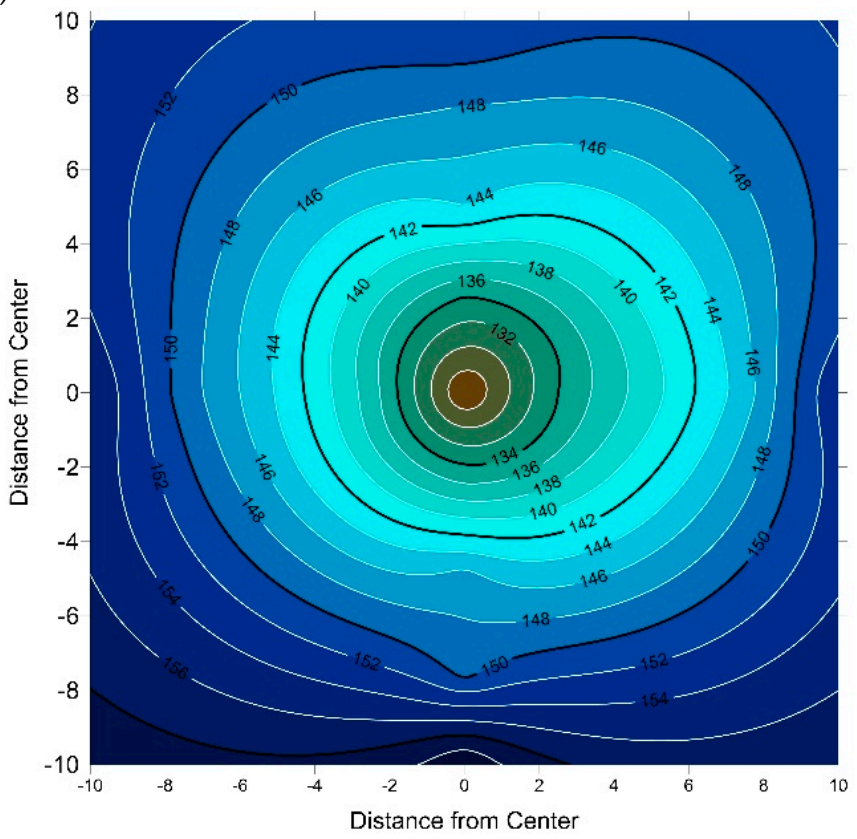

(c)

Figure 14. Color coded contour for the hardness values recorded on the transverse section (TS) of the Cu billets processed via ECAP processing after (a) 1-P, (b) 2-Bc and (c) 4-Bc.

Accordingly, from Figure 13 it is clear that higher hardness values were recorded at the periphery areas of the top surface of the billets', which diminished toward the center and the bottom parts. The hardness values varied, reaching $126 \mathrm{HV}$ at the sample top peripheral zone and decreasing up to $108 \mathrm{HV}$ at the sample bottom central area. It was observed that the relative uniformity of the billets' hardness was raised along the LS when processed via 2-Bc (Figure 13b), compared to the first pass, this increase was manifested from the peripheries to the centre of the rod, with hardness values varying, showing $115 \mathrm{HV}$ at the center and increasing to $129 \mathrm{HV}$ at the peripheries. Increasing the processing passes up to 4 -Bc resulted in a significant increase in the hardness values. The recorded results revealed increasing the hardness value up to $158 \mathrm{HV}$ in the top peripheral areas while the hardness 
value in the central zone increased to $127 \mathrm{HV}$ (Figure 13c). Table 3 lists the average hardness values measured at the peripheral and central regions and the mechanical properties of the AA billets before and after ECAP.

Table 3. Mechanical properties of commercial pure Cu processed via ECAP.

\begin{tabular}{|c|c|c|c|c|c|c|}
\hline \multirow{2}{*}{$\begin{array}{l}\text { Processing } \\
\text { Condition }\end{array}$} & \multirow{2}{*}{$\begin{array}{l}\text { Processing } \\
\text { Temperature }\end{array}$} & \multicolumn{2}{|c|}{ HV-Value } & \multirow{2}{*}{$\begin{array}{c}\text { YS } \\
(\mathrm{MPa})\end{array}$} & \multirow{2}{*}{$\begin{array}{l}\text { UTS } \\
\text { (MPa) }\end{array}$} & \multirow{2}{*}{$\begin{array}{c}\text { Elongation } \\
(\%)\end{array}$} \\
\hline & & Center & Periphery & & & \\
\hline AA & - & $55 \pm 2$ & $55 \pm 2$ & 122 & 170 & 41.5 \\
\hline 1-P & \multirow{3}{*}{ RT } & $108 \pm 2$ & $126 \pm 2$ & 280 & 299.5 & 25.3 \\
\hline $2-B c$ & & $115 \pm 2$ & $129 \pm 2$ & 324 & 364 & 25.3 \\
\hline $4-\mathrm{Bc}$ & & $127 \pm 2$ & $158 \pm 3$ & 272 & 381 & 30 \\
\hline $1-P$ & \multirow{2}{*}{$200^{\circ} \mathrm{C}$} & $102 \pm 1$ & $116 \pm 3$ & 292 & 302 & 26.8 \\
\hline $4-\mathrm{Bc}$ & & $113 \pm 2$ & $128 \pm 1$ & 292 & 330 & 28.5 \\
\hline
\end{tabular}

In addition, as shown in Figure 14, processing via 1-P revealed 96\% and 125\% rises in the hardness values at the center and peripheries, respectively, when put in comparison with the AA condition. This invariably implies that the distribution of hardness values has a large degree of inhomogeneity across the transverse section of the rod (Figure 14a). However, the hardness homogeneity of the billets across their transverse section correlated with the number of passes as shown in Figure 14b,c. Processing through 2-Bc showed increase in the recorded hardness results up to $7 \%$, and $5 \%$ in the central and peripheral areas, respectively compared to the 1-P condition. Additionally, 4-Bc correlated with rises in hardness values across the center and peripheries by $16.6 \%$ and $29 \%$ respectively, when compared with the 1-P condition.

Figures 15 and 16 show the hardness distribution of ECAPed $\mathrm{Cu}$ billets processed at $200^{\circ} \mathrm{C}$ through 1-P and 4-Bc along the sample's LS and TS. There was a visible enhancement in hardness homogeneity along the LS that occurs due to ECAP processing at $20{ }^{\circ} \mathrm{C}$ as shown in Figure 15 compared to RT processing (Figure 13). The hardness homogeneity between the central and peripheral regions in the LS showed an increase of $22 \%$ after being processed through 1-P at $200{ }^{\circ} \mathrm{C}$ (Figure 13a), compared to the sample processed through the same route (1-P) at RT, which concurs with [43]. The hardness homogeneity between the central and peripheral regions showed an increase of $50 \%$ compared to the counterparts processed at RT when the strain was increased up to 4-Bc, which agrees with [42]. A similar trend was visible in the hardness contour maps of the sample TS as shown in Figure 16. The uniform hardness distribution can be attributed to the higher strains achieved by processing multiple passes, which led to the stabilization of the sample's internal structure [21]. When processed at RT, the strain accumulating in the sample was higher, which resulted in a drastic increase in hardness, accompanied by the sample's heterogeneity being marginally improved. The samples processed through 1-P at $200{ }^{\circ} \mathrm{C}$ showed an increase in the hardness uniformity from the central region (102 HV) to the peripheral regions $(116 \mathrm{HV})$, shown in Figure 13. The sample processed through 4-Bc showed a slight variation of hardness values between the center $(113 \mathrm{HV})$ and the peripheral regions $(128 \mathrm{HV})$. 


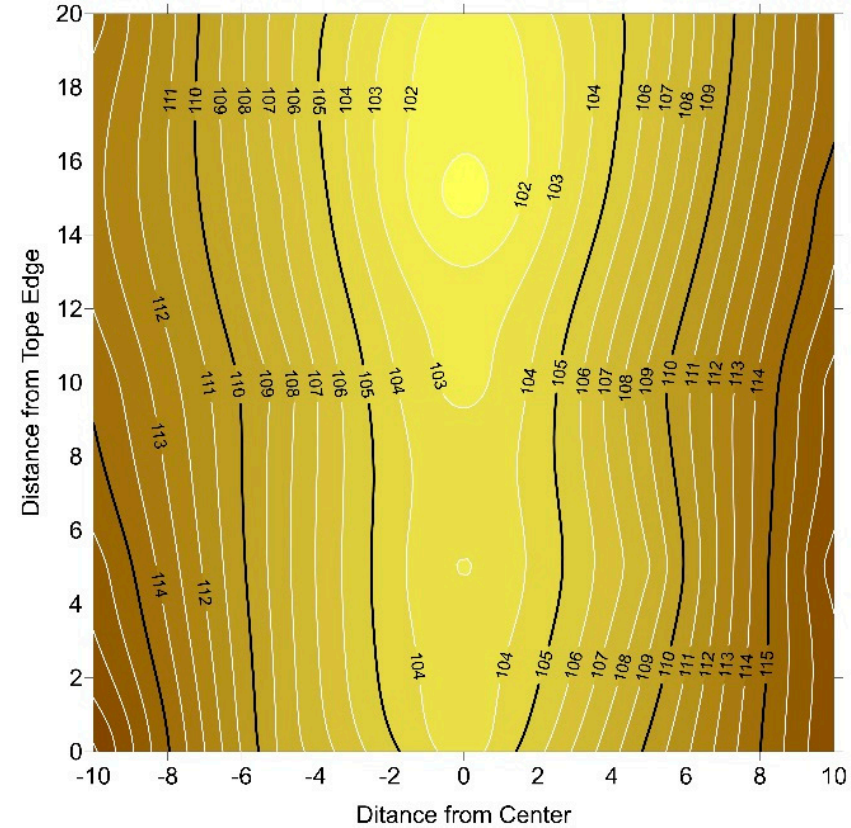

(a)

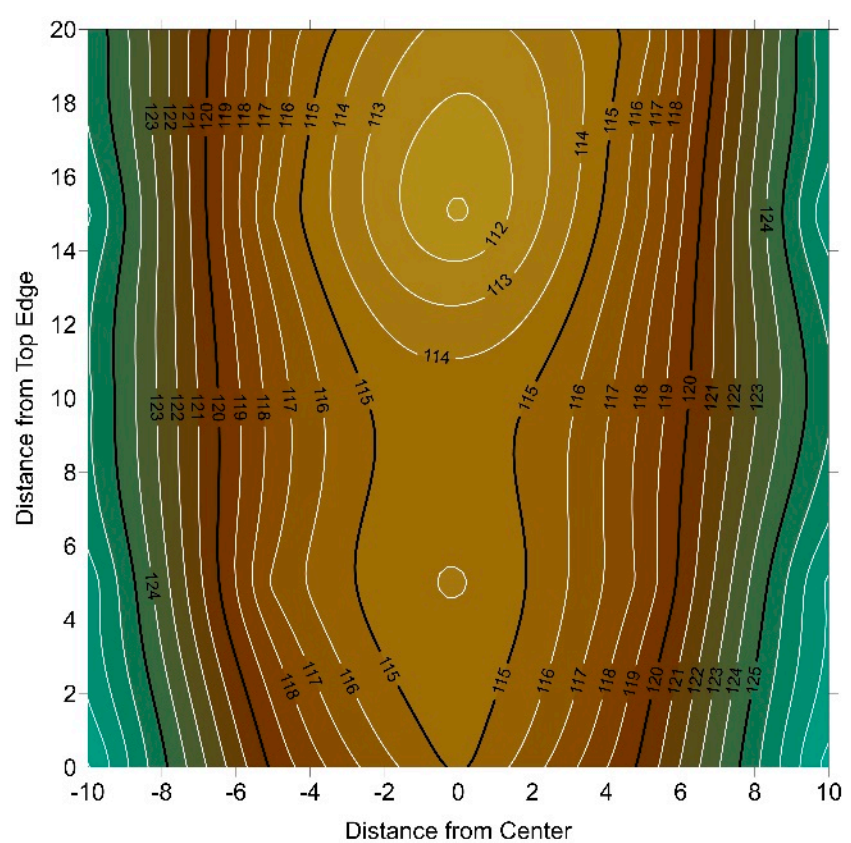

(b)

Figure 15. Color coded contour for the hardness values recorded on the LS of the Cu billets processed via ECAP through (a) $1-\mathrm{P}$ and (b) 4 -Bc at $200^{\circ} \mathrm{C}$.

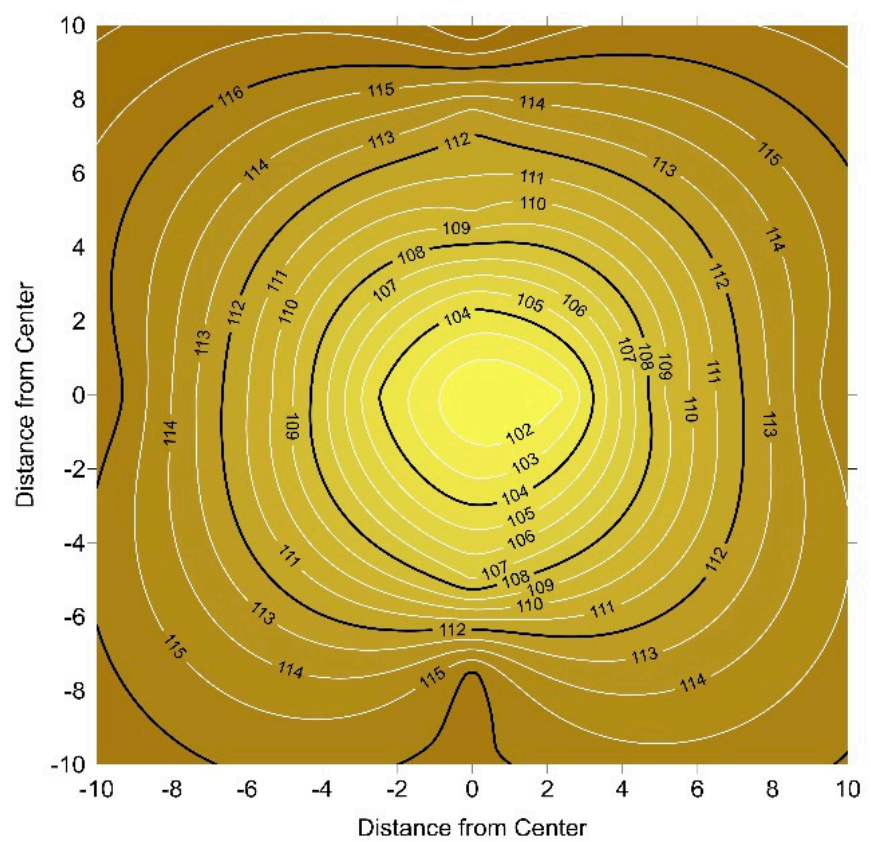

(a)

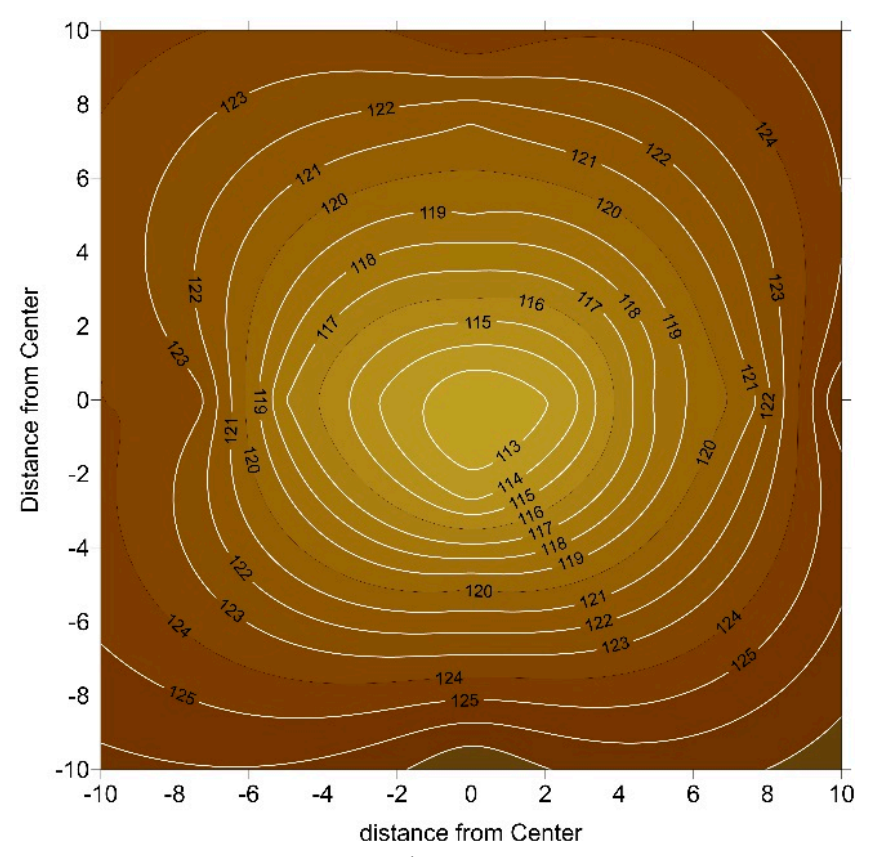

(b)

Figure 16. Color coded contour for the hardness values recorded on the TS of the $\mathrm{Cu}$ samples processed via ECAP through (a) $1-\mathrm{P}$ and (b) $4-\mathrm{Bc}$ at $200^{\circ} \mathrm{C}$.

From examining Figure 15a, a trend emerged concerning hardness values. The highest hardness values were recorded at the top of the sample near the edges. From there, we noticed that their values decrease vertically until the bottom edges. The data confirm this, as hardness values of $116 \mathrm{HV}$ were recorded left and right of the disc section's longitudinal axis, decreasing to $102 \mathrm{HV}$ as we moved toward the disc center; the lowest hardness value was $100.5 \mathrm{HV}$, recorded at the bottom central area (Figure 13a). 
The samples that went through 4-Bc processing showed a distribution of microhardness values, which were symmetrical on either side of the longitudinal central axis; Figure $15 \mathrm{~b}$ illustrates this. Moreover, the hardness values seemed to become more homogenous as we increased the number of passes, meaning that the 4-Bc samples had the highest microhardness distribution homogeneity (Figure 15b). So, as stated, the 4-Bc processing, at $200{ }^{\circ} \mathrm{C}$, resulted in a more highly uniform hardness distribution. The HV values recorded from the LS of the sample range from $128 \mathrm{HV}$ near the rod's peripheries to $111 \mathrm{HV}$ at the bottom of the central axis. A similar trend was noticed in the hardness distribution of the TS of both the ECAPed samples processed through 1-P (Figure 16a) and that processed through 4-Bc (Figure 16b) at $200{ }^{\circ} \mathrm{C}$ as more homogenous distribution of the hardness values from the ECAPed samples central to peripheral regions can be depicted.

It is worth mentioning here that the observed surge in hardness at the peripheral regions in comparison with the center is due to the friction between the rod and ECAP die walls [57]. The rod's cross section impacted the strain imposed on the billets, increasing the strain inhomogeneity' degree with the increase of the cross section; where the peripheries had higher strain while the center of the rod had lower strain. Accordingly, the enhancement in the hardness values after ECAP processing can be attributed to the strain accumulation through increasing the number of processing. It is worth mentioning here that ECAP processing is usually accompanied with production, multiplication and locking of dislocations processes, which results in the formation of LAGBs and HAGBs and, finally, the formation of UFG materials. In addition, it is commonly known that for the materials with moderate SFE such as $\mathrm{Cu}$, twining is an important deformation mechanism, which resulted in grain refinement in addition to the dislocation slip during ECAP processing. Accordingly, the UFG structured yielded from ECAP processing inhibits dislocation glide thus leading to strengthening the material according to the Hall-Petch equation [58,59]. As mentioned above, it is reasonable to conclude that the strengthening of ECAP samples is generally thought of as the refinement of grains, formation of twins and accumulation of dislocations [12]. These hardness findings show good agreement with the developed EBSD maps in Figure 7 and with the pole figures shown in Figure 9. Indeed, the EBSD observation showed that processing through ECAP via multiple passes led to increasing the percentage of UFG $(<1 \mu \mathrm{m})$ up to $33 \%$ as shown in Figure 7 . In addition, the increase of the percentage of LAGBs and HAGBs after ECAP as shown in Figures 6-8, processing hindered the mobile dislocations effectively. Hence, the refined grains make a significant contribution to improved hardness.

Table 3 shows the tensile properties of both the AA and ECAPed Cu samples. Tensile testing showed that the ECAPed samples had higher yield strength (YS) and ultimate tensile strength (UTS) than the AA samples. This increase in YS and UTS came at the expense of reduced ductility. These properties are expected since the samples underwent refinement in grain size and a relative increase in HAGBs $[60,61]$ as the number of passes increased; the recorded increase in HV, YS and UTS values after being processed via ECAP confirm this. As observed in Table 3, 1-P processing results in higher YS and UTS, processing any further resulted in a gradual increase in YS and UTS, which agrees with the results of [62]. Drastic increases of $(129.5 \%)$ and $(76 \%)$ in YS and UTS, respectively, were noticed after processing through 1-P at RT, alongside a reduction of $39 \%$ in the ductility, compared to the AA samples. However, the tensile properties exhibited from 1-P revealed insignificant change when the sample was processed further up to 4-Bc at RT. Table 3 shows that there was not any evident difference in YS, or UTS between the 1-P warm processed samples and 1-P RT processed samples where the YS, UTS and ductility had improved by $4.2 \%, 0.8 \%$ and $4.7 \%$, respectively. The tensile properties of the $200{ }^{\circ} \mathrm{C}$ processed $4-\mathrm{Bc}$ samples showed $7.35 \%$ increase in the YS coupled with $13.3 \%$ and $5 \%$ reduction in the UTS and ductility, respectively, compared to the sample processed through 4-Bc at RT. These results are consistent with the outcomes of a recent study [13,60]. These findings confirm that the warm processing conditions still favor the material strength increase until the first pass [61]. On the other hand, the subsequent decrease of strength in further warm ECAP 
passes can be explained by the occurrence of dynamic recovery and discontinuous dynamic recrystallization, which leads to the elimination of dislocations [61].

\section{Conclusions}

In this study, the effect of ECAP processing on the microstructural evolution, crystallographic texture and hardness variation of commercial purity $\mathrm{Cu}$ processed at $\mathrm{RT}$ and $200{ }^{\circ} \mathrm{C}$ for up to 4 passes of route Bc was comprehensively investigated. The following conclusions can be drawn:

1. The FE numerical model revealed that processing via 1-P of pure copper experienced a max effective strain of about 0.74 .

2. The microstructure obtained after 1-P exhibited finer equiaxed grains down to submicrons with a significant increase in the high angle boundaries, the substructures and high density of twin boundaries.

3. The microstructure was homogenous through the sample cross section and increasing the imposed strain up to 4-Bc had resulted in an increase of the deformed microstructural features.

4. The crystallographic texture after 4-Bc at RT was a strong simple shear texture displaying about 7 times random.

5. Conducting the ECAP processing at $200^{\circ} \mathrm{C}$ resulted in a severely deformed microstructure with the highest fraction of submicron grains and high density of substructures was also observed.

6. Processing through 1-P revealed an increase of the hardness values by $125 \%$ and $96 \%$ in the peripheral and central regions compared to the as-annealed counterpart.

7. Further straining up to 4-Bc revealed an additional increase of the hardness values by $29 \%$ and $16.6 \%$ in the peripheral and central regions compared to the 1-P counterpart.

Author Contributions: Conceptualization, A.I.A., H.A.E.-H. and W.H.E.-G.; methodology, A.I.A., M.M.Z.A.; Y.Z.; H.A.E.-H.; and W.H.E.-G.; validation A.I.A., M.M.Z.A.; Y.Z.; H.A.E.-H.; M.O.A. and W.H.E.-G. formal analysis, and M.M.Z.A.; Y.Z. and W.H.E.-G.; investigation, A.I.A., M.M.Z.A.; Y.Z.; H.A.E.-H.; M.O.A. and W.H.E.-G.; data curation, M.M.Z.A.; Y.Z. and W.H.E.-G.; writing-original draft preparation, M.M.Z.A.; Y.Z. and W.H.E.-G.; writing—review and editing, M.M.Z.A.; Y.Z.; M.O.A. and W.H.E.-G.; project administration, A.I.A., H.A.E.-H. and W.H.E.-G. All authors have read and agreed to the published version of the manuscript.

Funding: This research received no external funding.

Institutional Review Board Statement: Not applicable.

Informed Consent Statement: Not applicable.

Data Availability Statement: All the raw data supporting the conclusion of this paper were provided by the authors.

Acknowledgments: Researchers would like to thank the Deanship of Scientific Research, Qassim University, for funding publication of this project.

Conflicts of Interest: The authors declare no conflict of interest.

\section{References}

1. Ma, M.; Li, Z.; Qiu, W.; Xiao, Z.; Zhao, Z.; Jiang, Y.; Xia, Z.; Huang, H. Development of homogeneity in a Cu-Mg-Ca alloy processed by equal channel angular pressing. J. Alloys Compd. 2020, 820, 153112. [CrossRef]

2. Ma, M.; Li, Z.; Qiu, W.; Xiao, Z.; Zhao, Z.; Jiang, Y. Microstructure and properties of Cu-Mg-Ca alloy processed by equal channel angular pressing. J. Alloys Compd. 2019, 788, 50-60. [CrossRef]

3. Abib, K.; Balanos, J.A.M.; Alili, B.; Bradai, D. On the microstructure and texture of Cu-Cr-Zr alloy after severe plastic deformation by ECAP. Mater. Charact. 2016, 112, 252-258. [CrossRef]

4. Krishna, S.C.; Chawake, N.; Kottada, R.S.; Jha, A.K.; Pant, B.; Venkitakrishnan, P.V. High Strength and Good Ductility in Cu-3Ag-0.5Zr Alloy by Cryo-Rolling and Aging. J. Mater. Eng. Perform. 2017, 26, 350-357. [CrossRef] 
5. Murashkin, M.Y.; Sabirov, I.; Sauvage, X.; Valiev, R.Z. Nanostructured Al and Cu alloys with superior strength and electrical conductivity. J. Mater. Sci. 2016, 51, 33-49. [CrossRef]

6. Ebrahimi, M.; Shaeri, M.H.; Gode, C.; Armoon, H.; Shamsborhan, M. The synergistic effect of dilute alloying and nanostructuring of copper on the improvement of mechanical and tribological response. Compos. Part B Eng. 2019, 164, 508-516. [CrossRef]

7. Islamgaliev, R.K.; Nesterov, K.M.; Valiev, R.Z. Structure, strength, and electric conductivity of a Cu-Cr copper-based alloy subjected to severe plastic deformation. Phys. Met. Metallogr. 2015, 116, 209-218. [CrossRef]

8. Král, P.; Dvořák, J.; Kvapilová, M.; Blum, W.; Sklenička, V. The influence of long-term annealing at room temperature on creep behaviour of ECAP-processed copper. Mater. Lett. 2017, 188, 235-238. [CrossRef]

9. Huang, R.; Zhu, D.; Liao, X.; Yan, Q. Effect of ECAP Process and Subsequent Annealing on Microstructure and Properties of Cu-0.25Se-0.25Te Alloy. J. Electron. Mater. 2020, 49, 2617-2624. [CrossRef]

10. Bochvar, N.R.; Rybalchenko, O.V.; Shangina, D.V.; Dobatkin, S.V. Effect of equal-channel angular pressing on the precipitation kinetics in Cu-Cr-Hf alloys. Mater. Sci. Eng. A 2019, 757, 84-87. [CrossRef]

11. Xu, X.X.; Nie, F.L.; Zhang, J.X.; Zheng, W.; Zheng, Y.F.; Hu, C.; Yang, G. Corrosion and ion release behavior of ultra-fine grained bulk pure copper fabricated by ECAP in Hanks solution as potential biomaterial for contraception. Mater. Lett. 2010, 64, 524-527. [CrossRef]

12. Patil, A.; Bontha, S.; Ramesh, M.R. Effect of ECAP on sliding wear behaviour of Mg-Zn-Gd-Zr alloy. Mater. Today Proc. 2020, 20, 97-102. [CrossRef]

13. Safari, M.; Joudaki, J. Effect of Temperature on Strength and Hardness in Multi-pass Equal Channel Angular Pressing (ECAP) of Aluminum Alloys. Trans. Indian Inst. Met. 2020, 73, 619-627. [CrossRef]

14. Kong, Y.; Pu, Q.; Jia, Z.; Liu, M.; Roven, H.J.; Jia, J.; Liu, Q. Microstructure and property evolution of Al-0.4Fe-0.15Zr-0.25Er alloy processed by high pressure torsion. J. Alloys Compd. 2020, 824, 153949. [CrossRef]

15. Bednarczyk, W.; Kawałko, J.; Watroba, M.; Gao, N.; Starink, M.J.; Bała, P.; Langdon, T.G. Microstructure and mechanical properties of a Zn-0.5Cu alloy processed by high-pressure torsion. Mater. Sci. Eng. A 2020, 776, 139047. [CrossRef]

16. El-Garaihy, W.H.; Rassoul, E.S.M.A.; Salem, H.G. Consolidation of high performance AA6061 and AA6061-SiCp composite processed by high pressure torsion. In Materials Science Forum; Trans Tech Publications: Zurich, Switzerland, 2014; pp. 2623-2628.

17. Salem, H.G.; El-Garaihy, W.H.; Rassoul, E.S.M.A. Influence of high pressure torsion on the consolidation behavior and mechanical properties of AA6061-SiCP composites powders. TMS Annu. Meet. 2012, 1, 553-560.

18. Vu, V.Q.; Prokof'eva, O.; Toth, L.S.; Usov, V.; Shkatulyak, N.; Estrin, Y.; Kulagin, R.; Varyukhin, V.; Beygelzimer, Y. Obtaining hexagon-shaped billets of copper with gradient structure by twist extrusion. Mater. Charact. 2019, 153, 215-223. [CrossRef]

19. Fouad, D.M.; Moataz, A.; El-Garaihy, W.H.; Salem, H.G. Numerical and experimental analysis of multi-channel spiral twist extrusion processing of AA5083. Mater. Sci. Eng. A 2019, 764, 138216. [CrossRef]

20. Fouad, D.M.; El-Garaihy, W.H.; Ahmed, M.M.Z.; El-Sayed Seleman, M.M.; Salem, H.G. Influence of multi-channel spiral twist extrusion (MCSTE) processing on structural evolution, crystallographic texture and mechanical properties of AA1100. Mater. Sci. Eng. A 2018, 737, 166-175. [CrossRef]

21. El-Garaihy, W.H.; Fouad, D.M.; Salem, H.G. Multi-channel Spiral Twist Extrusion (MCSTE): A Novel Severe Plastic Deformation Technique for Grain Refinement. Metall. Mater. Trans. A Phys. Metall. Mater. Sci. 2018, 49, 2854-2864. [CrossRef]

22. Mansouri, H.; Eghbali, B.; Afrand, M. Producing multi-layer composite of stainless steel/aluminum/copper by accumulative roll bonding (ARB) process. J. Manuf. Process. 2019, 46, 298-303. [CrossRef]

23. Shaeri, M.; Karimi Taheri, K.; Karimi Taheri, A.; Shaeri, M.H. An Investigation on Microstructure Evolution, Mechanical Properties, and Strain Aging of Mg-1.8Zn-0.7Si-0.4Ca Biomedical Alloy Processed by Equal Channel Angular Pressing. J. Mater. Eng. Perform. 2019, 28, 5207-5219. [CrossRef]

24. Gopal, R.; Thangadurai, K.R.; Thirunavukkarasu, K. Behavior of ECAP processed copper electrodes in electrical discharge machining of AISI H13 steel. Mater. Today Proc. 2020, 21, 295-298. [CrossRef]

25. Lugo, N.; Llorca, N.; Cabrera, J.M.; Horita, Z. Microstructures and mechanical properties of pure copper deformed severely by equal-channel angular pressing and high pressure torsion. Mater. Sci. Eng. A 2008, 477, 366-371. [CrossRef]

26. Habibi, A.; Ketabchi, M.; Eskandarzadeh, M. Nano-grained pure copper with high-strength and high-conductivity produced by equal channel angular rolling process. J. Mater. Process. Technol. 2011, 211, 1085-1090. [CrossRef]

27. Molodova, X.; Khorashadizadeh, A.; Gottstein, G.; Winning, M.; Hellmig, R.J. Thermal stability of ECAP processed pure Cu and CuZr. Z. Met. Res. Adv. Tech. 2007, 98, 269-275. [CrossRef]

28. El-Danaf, E.A.; Soliman, M.S.; Almajid, A.A.; El-Rayes, M.M. Enhancement of mechanical properties and grain size refinement of commercial purity aluminum 1050 processed by ECAP. Mater. Sci. Eng. A 2007, 458, 226-234. [CrossRef]

29. Bagherzadeh, S.; Abrinia, K.; Han, Q. Analysis of plastic deformation behavior of ultrafine-grained aluminum processed by the newly developed ultrasonic vibration enhanced ECAP: Simulation and experiments. J. Manuf. Process. 2020, 50, 485-497. [CrossRef]

30. Srinivasarao, B.; Oh-ishi, K.; Ohkubo, T.; Hono, K. Bimodally grained high-strength Fe fabricated by mechanical alloying and spark plasma sintering. Acta Mater. 2009, 57, 3277-3286. [CrossRef] 
31. Krajňák, T.; Minárik, P.; Stráská, J.; Gubicza, J.; Dluhoš, L.; Máthis, K.; Janeček, M. Influence of temperature of ECAP processing on the microstructure and microhardness of as-cast AX41 alloy. J. Mater. Sci. 2020, 55, 3118-3129. [CrossRef]

32. Jia, H.; Li, Y. Texture evolution of an Al-8Zn alloy during ECAP and post-ECAP isothermal annealing. Mater. Charact. 2019, 155, 109794. [CrossRef]

33. Naik, G.M.; Narendranath, S.; Kumar, S.S.S. Effect of ECAP Die Angles on Microstructure Mechanical Properties and Corrosion Behavior of AZ80 Mg Alloy. J. Mater. Eng. Perform. 2019, 28, 2610-2619. [CrossRef]

34. Lugo, N.; Llorca, N.; Suñol, J.J.; Cabrera, J.M. Thermal stability of ultrafine grains size of pure copper obtained by equal-channel angular pressing. J. Mater. Sci. 2010, 45, 2264-2273. [CrossRef]

35. Valiev, R.Z.; Krasilnikov, N.A.; Tsenev, N.K. Plastic deformation of alloys with submicron-grained structure. Mater. Sci. Eng. A 1991, 137, 35-40. [CrossRef]

36. Iwahashi, Y.; Horita, Z.; Nemoto, M.; Langdon, T.G. The process of grain refinement in equal-channel angular pressing. Acta Mater. 1998, 46, 3317-3331. [CrossRef]

37. Wang, H.; Ban, C.; Zhao, N.; Zhu, Q.; Cui, J. Effective grain refinement of pure Cu processed by new route of equal channel angular pressing. Mater. Sci. Eng. A 2019, 751, 246-252. [CrossRef]

38. Guo, T.; Wang, C.; Li, Q.; Wu, Y.; Tang, X. Texture Evolution and Strengthening Behavior of Single Crystal Copper During Equal Channel Angular Pressing. Xiyou Jinshu Cailiao Yu Gongcheng Rare Met. Mater. Eng. 2019, 48, 1065-1073.

39. Blum, W.; Dvořák, J.; Král, P.; Sklenička, V. Dynamic grain coarsening in creep of pure Cu at $0.42 \mathrm{Tm}$ after predeformation by ECAP. Mater. Sci. Eng. A 2018, 731, 520-529. [CrossRef]

40. Zhu, C.F.; Du, F.P.; Jiao, Q.Y.; Wang, X.M.; Chen, A.Y.; Liu, F.; Pan, D. Microstructure and strength of pure Cu with large grains processed by equal channel angular pressing. Mater. Des. 2013, 52, 23-29. [CrossRef]

41. Deng, G.Y.; Lu, C.; Su, L.H.; Liu, X.H.; Tieu, A.K. Modeling texture evolution during ECAP of copper single crystal by crystal plasticity FEM. Mater. Sci. Eng. A 2012, 534, 68-74. [CrossRef]

42. Blum, W.; Dvořák, J.; Král, P.; Eisenlohr, P.; Sklenička, V. Effect of grain refinement by ECAP on creep of pure Cu. Mater. Sci. Eng. A 2014, 590, 423-432. [CrossRef]

43. Ebrahimi, M.; Gode, C. Severely deformed copper by equal channel angular pressing. Prog. Nat. Sci. Mater. Int. 2017, 27, 244-250. [CrossRef]

44. Deng, G.Y.; Lu, C.; Tieu, A.K.; Su, L.H.; Huynh, N.N.; Liu, X.H. Crystal plasticity investigation of friction effect on texture evolution of Al single crystal during ECAP. J. Mater. Sci. 2010, 45, 4711-4717. [CrossRef]

45. Lee, H.H.; Kim, W.; Jung, K.C.; Seo, S.; Lee, J.K.; Park, H.L.; Park, K.-T.; Kim, H.S. Circumferential twisting during route B equal-channel angular pressing. J. Mater. Process. Technol. 2018, 259, 305-311. [CrossRef]

46. Abd El Aal, M.I. 3D FEM simulations and experimental validation of plastic deformation of pure aluminum deformed by ECAP and combination of ECAP and direct extrusion. Trans. Nonferrous. Met. Soc. China 2017, 27, 1338-1352. [CrossRef]

47. Spirdione, J.; Ghonem, H. Dynamic flow stress of fine grain material processed using equal channel angular pressing. Mater. Sci. Eng. A 2017, 698, 256-267. [CrossRef]

48. El Mahallawy, N.; Shehata, F.A.; Abd el Hameed, M.; Abd el Aal, M.I.; Kim, H.S. 3D FEM simulations for the homogeneity of plastic deformation in Al-Cu alloys during ECAP. Mater. Sci. Eng. A 2010, 527, 1404-1410. [CrossRef]

49. Rollett, A.; Humphreys, F.; Rohrer, G.S.; Hatherly, M. Recrystallization and Related Annealing Phenomena, 2nd ed.; Elsevier: Amsterdam, The Netherlands, 2004; pp. 1-628.

50. Higuera-Cobos, O.F.; Cabrera, J.M. Mechanical, microstructural and electrical evolution of commercially pure copper processed by equal channel angular extrusion. Mater. Sci. Eng. A 2013, 571, 103-114. [CrossRef]

51. Suwas, S.; Tóth, L.S.; Fundenberger, J.J.; Eberhardt, A.; Skrotzki, W. Evolution of crystallographic texture during equal channel angular extrusion of silver. Scr. Mater. 2003, 49, 1203-1208. [CrossRef]

52. Li, S.; Beyerlein, I.J.; Necker, C.T. On the Development of Microstructure and Texture Heterogeneity in ECAE via Route C. Acta Mater. 2006, 54, 1397-1408. [CrossRef]

53. Mishin, O.V.; Bowen, J.R. Through-Thickness Variations of Deformed and Annealed Microstructures in ECAE-Processed Copper. Metall. Mater. Trans. A 2009, 40A, 1684. [CrossRef]

54. Barnett, M.R.; Montheillet, F. The generation of new high-angle boundaries in aluminum during hot torsion. Acta Mater. 2002, 50, 2285-2296. [CrossRef]

55. Fonda, R.W.; Bingert, J.F. Texture variations in an aluminum friction stir weld. Scr. Mater. 2007, 57, 1052-1055. [CrossRef]

56. Djavanroodi, F.; Omranpour, B.; Ebrahimi, M.; Sedighi, M. Designing of ECAP parameters based on strain distribution uniformity. Prog. Nat. Sci. Mater. Int. 2012, 22, 452-460. [CrossRef]

57. Alateyah, A.I.; Aljohani, T.A.; Alawad, M.O.; El-Hafez, H.A.; Almutairi, A.N.; Alharbi, E.S.; Alhamada, R.; El-Garaihy, B.W.; El-Garaihy, W.H. Improved Corrosion Behavior of AZ31 Alloy through ECAP Processing. Metals 2021, 11, 363. [CrossRef]

58. Suresh, M.; Sharma, A.; More, A.; Kalsar, R.; Bisht, A.; Nayan, N.; Suwas, S. Effect of equal channel angular pressing (ECAP) on the evolution of texture, microstructure and mechanical properties in the Al-Cu-Li alloy AA2195. J. Alloys Compd. 2019, 785, 972-983. [CrossRef]

59. Elhefnawey, M.; Shuai, G.L.; Li, Z.; Nemat-Alla, M.; Zhang, D.T.; Li, L. On achieving superior strength for Al-Mg-Zn alloy adopting cold ECAP. Vacuum 2020, 174, 109191. [CrossRef] 
60. Shaeri, M.H.; Shaeri, M.; Ebrahimi, M.; Salehi, M.T.; Seyyedein, S.H. Effect of ECAP temperature on microstructure and mechanical properties of Al-Zn-Mg-Cu alloy. Prog. Nat. Sci. Mater. Int. 2016, 26, 182-191. [CrossRef]

61. Khelfa, T.; Muñoz-Bolaños, J.A.; Li, F.; Cabrera-Marrero, J.M.; Khitouni, M. Microstructure and Mechanical Properties of AA6082-T6 by ECAP under Warm Processing. Met. Mater. Int. 2020, 26, 1247-1261. [CrossRef]

62. Tong, Y.X.; Wang, Y.; Qian, Z.M.; Zhang, D.T.; Li, L.; Zheng, Y.F. Achieving High Strength and High Electrical Conductivity in a CuCrZr Alloy Using Equal-Channel Angular Pressing. Acta Metall. Sin. 2018, 31, 1084-1088. [CrossRef] 